\title{
Proliferating NG2-Cell-Dependent Angiogenesis and Scar Formation Alter Axon Growth and Functional Recovery After Spinal Cord Injury in Mice
}

\author{
(Doe C. Hesp, ${ }^{1,2}$ Rim Y. Yoseph, ${ }^{1,2}$ Ryusuke Suzuki, ${ }^{4}$ Peter Jukkola, ${ }^{4}{ }^{-C}$ Claire Wilson, ${ }^{2}{ }^{-1}$ Akiko Nishiyama, ${ }^{4}$ \\ and $\odot$ Dana M. McTigue ${ }^{2,3}$ \\ ${ }^{1}$ Neuroscience Graduate Program, ${ }^{2}$ Center for Brain and Spinal Cord Repair, ${ }^{3}$ Department of Neuroscience, The Ohio State University, Columbus, Ohio \\ 43210, and ${ }^{4}$ Department of Physiology and Neurobiology, University of Connecticut, Storrs, Connecticut 06269
}

\begin{abstract}
Spinal cord injury (SCI) induces a centralized fibrotic scar surrounded by a reactive glial scar at the lesion site. The origin of these scars is thought to be perivascular cells entering lesions on ingrowing blood vessels and reactive astrocytes, respectively. However, two NG2-expressing cell populations, pericytes and glia, may also influence scar formation. In the periphery, new blood vessel growth requires proliferating $\mathrm{NG}_{2}{ }^{+}$pericytes; if this were also true in the CNS, then the fibrotic scar would depend on dividing NG2 ${ }^{+}$pericytes. $\mathrm{NG}^{+}$glial cells (also called oligodendrocyte progenitors or polydendrocytes) also proliferate after SCI and accumulate in large numbers among astrocytes in the glial scar. Their effect there, if any, is unknown. We show that proliferating $\mathrm{NG}^{+}$pericytes and glia largely segregate into the fibrotic and glial scars, respectively; therefore, we used a thymidine kinase/ganciclovir paradigm to ablate both dividing $\mathrm{NG} 2{ }^{+}$cell populations to determine whether either scar was altered. Results reveal that loss of proliferating NG2 ${ }^{+}$pericytes in the lesion prevented intralesion angiogenesis and completely abolished the fibrotic scar. The glial scar was also altered in the absence of acutely dividing NG2 ${ }^{+}$cells, displaying discontinuous borders and significantly reduced GFAP density. Collectively, these changes enhanced edema, prolonged hemorrhage, and impaired forelimb functional recovery. Interestingly, after halting GCV at $14 \mathrm{~d}$ postinjury, scar elements and vessels entered the lesions over the next $7 \mathrm{~d}$, as did large numbers of axons that were not present in controls. Collectively, these data reveal that acutely dividing $\mathrm{NG2}^{+}$pericytes and glia play fundamental roles in post-SCI tissue remodeling.
\end{abstract}

Key words: fibroblast; glial scar; laminin; oligodendrocyte progenitor; pericyte; spinal cord injury

Significance Statement

Spinal cord injury (SCI) is characterized by formation of astrocytic and fibrotic scars, both of which are necessary for lesion repair. $\mathrm{NG}{ }^{+}$cells may influence both scar-forming processes. This study used a novel transgenic mouse paradigm to ablate proliferating $\mathrm{NG} 2{ }^{+}$cells after SCI to better understand their role in repair. For the first time, our data show that dividing NG2 ${ }^{+}$pericytes are required for post-SCI angiogenesis, which in turn is needed for fibrotic scar formation. Moreover, loss of cycling NG2 ${ }^{+}$glia and pericytes caused significant multicellular tissue changes, including altered astrocyte responses and impaired functional recovery. This work reveals previously unknown ways in which proliferating NG2 ${ }^{+}$cells contribute to endogenous repair after SCI.

\section{Introduction}

Traumatic spinal cord injury (SCI) is characterized by glial and fibrotic scars, extracellular matrix (ECM) deposition, and angio-

Received Dec. 22, 2016; revised Nov. 18, 2017; accepted Dec. 17, 2017.

Author contributions: Z.C.H., R.S., A.N., and D.M.M. designed research; Z.C.H., R.Y.Y., R.S., P.J., C.W., and A.N. performed research; Z.C.H., R.Y.Y., P.J., C.W., and D.M.M. analyzed data; Z.C.H. and D.M.M. wrote the paper.

This work was supported by the National Institutes of Health (Grants NS043246 and P30-NS045758 to D.M.M., Grant NS095606 to Z.C.H., and Grants NS049267 and NS073425 to A.N.). Images presented in this report were generated using the instruments and services at the Campus Microscopy and Imaging Facility and Department of Neuroscience Imaging Core, The Ohio State University. We thank Ping Wei and Feng Qin Yin for excellent technical assistance.

The authors declare no competing financial interests. genesis (Mautes et al., 2000; Loy et al., 2002; Jakeman et al., 2014; Zhu et al., 2015). The scars are essential for lesion repair, and eliminating either impairs wound closure and exacerbates tissue loss. The central fibrotic scar is composed of fibroblasts and dense ECM components (Jakeman et al., 2000; Göritz et al., 2011; Soderblom et al., 2013). ECM deposition is a prerequisite for wound healing, including within the spinal cord, since spinal transection sites do not close in the absence of fibrotic scars (Klapka et al.,

Correspondence should be addressed to Dr. Dana McTigue, Department of Neuroscience, 692 Biomedical Research Tower, 460 W 12th Ave., Columbus, 0H 43210. E-mail: dana.mctigue@osumc.edu.

DOI:10.1523/JNEUROSCI.3953-16.2017

Copyright $(\odot 2018$ the authors $\quad 0270-6474 / 18 / 381366-17 \$ 15.00 / 0$ 
2005; Darby and Hewitson, 2007; Göritz et al., 2011). Previous SCI studies demonstrated that fibroblast progenitors produce this scar, including a subset of Glast ${ }^{+}$pericytes (Göritz et al., 2011) and/or col $1 \alpha 1^{+} \mathrm{NG}^{-}$perivascular cells (Soderblom et al., 2013). It is thought that these progenitors "ride" blood vessels as they enter SCI lesions, after which they detach and differentiate into scarproducing fibroblasts. Therefore, fibrotic scar formation likely depends on post-SCI angiogenesis.

The glial scar encircles the fibrotic scar. Ablating proliferating astrocytes after SCI abolishes this scar, exaggerates tissue loss, and impairs functional recovery (Faulkner et al., 2004). Although both scars are essential for lesion containment, they are mutually exclusive in terms of territory, with astrocytes and fibroblasts forming separate domains shortly after injury (Bundesen et al., 2003).

We hypothesize that formation of both scars also depends on proliferating $\mathrm{NG}_{2}{ }^{+}$cells, which include pericytes and glia. $\mathrm{NG} 2{ }^{+}$ pericytes are crucial for developmental and tumor-induced angiogenesis (Ozerdem and Stallcup, 2003; Huang et al., 2010); here, we predict that they are also required for angiogenesis and fibrotic scar formation. Our data verify that $\mathrm{NG}^{+}$glia do not enter fibrotic lesions, as noted before (Hackett and Lee, 2016), and therefore are unlikely to influence fibrotic scars; however, they do accumulate within glial scars in rodent and human SCI (Tan et al., 2005; Tripathi and McTigue, 2007; Buss et al., 2009; Hesp et al., 2015; Church et al., 2016; Hackett and Lee, 2016). Their effect on glial scar dynamics, however, is unknown.

Here, our data show important differences between dividing $\mathrm{NG}_{2}{ }^{+}$glia and pericytes. Dividing $\mathrm{NG}_{2}{ }^{+}$glia outnumber dividing $\mathrm{NG}_{2}{ }^{+}$pericytes up to 30 -fold, but are restricted to the glial scar and spared tissue, whereas dividing $\mathrm{NG} 2{ }^{+}$pericytes enter lesions concomitant with angiogenesis. Because of their separate domains and numbers, we used a thymidine kinase/ganciclovir (Tk/GCV) paradigm in NG2-Tk mice to eliminate both populations to address two questions: (1) are proliferating $\mathrm{NG}^{+}{ }^{+}$pericytes necessary for intralesion angiogenesis and fibrotic scar formation? and (2) does eliminating $\mathrm{NG}^{+}$glia (and a small subset of pericytes) alter glial scar formation?

First, pericyte proliferation was tracked after unilateral cervical SCI, which revealed peak proliferation at $3 \mathrm{~d}$ postinjury (dpi); interestingly, only $\sim 30 \%$ of dividing pericytes expressed NG2 and would be vulnerable to GCV. Despite this low percentage, their ablation completely prevented intralesion angiogenesis and fibrotic scar formation. The astrocytic scar was also altered by $\mathrm{NG}^{+}{ }^{+}$cell ablation; astrocytic labeling was significantly less dense and glial scar boundaries were discontinuous rather than displaying sharp borders. Given the abundance of proliferating $\mathrm{NG}_{2}{ }^{+}$ glia in this region by $7 \mathrm{dpi}$, a time when dividing $\mathrm{NG}^{+}$glia outnumbered $\mathrm{NG}^{+}$pericytes by $>25$-fold, the balance of glial scar changes likely results from NG ${ }^{+}$glia loss. Scar disruption enhanced edema and prolonged hemorrhage, but did not exacerbate spared tissue loss. When GCV was stopped at $14 \mathrm{dpi}$ and tissue examined $7 \mathrm{~d}$ later, lesions contained blood vessels, fibrotic elements, $\mathrm{NG}^{+}{ }^{+}$cells, and, surprisingly, a significant number of axons. Therefore, acute $\mathrm{NG}^{+}$cell ablation altered the lesion microenvironment in a way that enhanced subsequent axon growth in conjunction with formation of "looser" astrocytic and fibrotic scars, in contrast to control mice with few intralesion axons. Functionally, forelimb locomotion was persistently impaired in treated mice. Collectively, these data reveal novel roles for proliferating $\mathrm{NG}_{2}{ }^{+}$pericytes and glia in scar formation and lesion dynamics after SCI.
Table 1. Experimental groups and group sizes

\begin{tabular}{llcl}
\hline Group & Treatment & Day post-SCl & $n$ \\
\hline HSVtk & GCV & 7 & 7 \\
& & 11 & 5 \\
HSVtk & & 21 & 8 \\
& Saline & 7 & 6 \\
Wild-type & & 11 & 5 \\
Wild-type & GCV & 21 & 8 \\
& None & 11 & 4 \\
& & Naive & 4 \\
& & 1 & 4 \\
& & 3 & 4 \\
& & 7 & 4 \\
\hline
\end{tabular}

\section{Materials and Methods}

Experimental design. Two SCI mouse experiments were used in this study. In the first experiment, a time course analysis on C5 unilateral SCI in wild-type mice was conducted. In the second, wild-type or NG2-Tk mice received a C5 unilateral SCI followed by intracerebroventricular delivery of GCV or saline for 7-14 d. A subset of mice had intracerebral pumps removed at $14 \mathrm{~d}$ and survived until $21 \mathrm{~d}$. The $7 \mathrm{~d}$ and $21 \mathrm{~d}$ groups include a set of replicate experiments in which identical histological and behavioral results were observed in both studies. See Table 1 for experimental cohorts and group sizes, and Figure 2 for schematic representations of transgenic mouse experiments. Details of these procedures and experiments are described below.

Generation of transgenic mice. To ablate dividing reactive $\mathrm{NG}^{+}{ }^{+}$cells selectively, a novel transgenic mouse line was generated in which cells expressing NG2 also express Tk from herpes simplex virus (HSV) (NG2-Tk mice). Similar mouse paradigms have been used previously to ablate proliferating astrocytes (Faulkner et al., 2004) and $\mathrm{CD}_{11 \mathrm{~b}}{ }^{+}$microglia in vivo (Gowing et al., 2006). In this model, cells expressing Tk convert the antiviral agent GCV from an inert prodrug into a cytotoxic triphosphate, which is incorporated into the dividing genome, causing cell cycle arrest and apoptosis (Tomicic et al., 2002). Therefore, in NG2-Tk mice, exposure to GCV ablates recombined proliferating $\mathrm{NG}^{+}{ }^{+}$cells.

NG2-tk bacterial artificial chromosome (BAC) transgenic mice were generated using the RPCI-23 C57BL/6J mouse BAC clone in pBACe3.6 $\mathrm{BAC}$ vector that contained the entire 33.97kb Cspg4 gene flanked by 60 $\mathrm{kb}$ and $114 \mathrm{~kb}$ of $5^{\prime}$ and $3^{\prime}$ flanking sequences, respectively. The DsRed coding sequence in the NG2-DsRed BAC building vector ( $\mathrm{Zhu}$ et al., 2008) was replaced with that of the HSV1-Tk coding sequence obtained from Dr. Michael Sofroniew (University of California, Los Angeles), as described previously (Bush et al., 1998). The recombineered NG2-tk BAC was linearized and injected into fertilized oocytes using the Gene Targeting and Transgenic Facility at the University Connecticut Farmington. Details of the NG2tkBAC transgenic mice are described elsewhere (J.P. and A.N., unpublished data).

Quantification of TK recombination efficiency. Three-month-old NG2HSV:TK mice $(n=3)$ were perfused with PLP fixative containing $4 \%$ paraformaldehyde and immunolabeled according to previously published methods (Serwanski et al., 2017). Then, $40 \mu \mathrm{m}$ transverse spinal cord sections were sectioned on a Leica 3050 S cryostat and thawmounted onto microscope slides. Sections were immunostained using goat anti-platelet-derived growth factor receptor $\alpha$ (anti-PDGFR $\alpha$; R and D Systems catalog \#AF1062; a marker of NG2 cells) and rabbit polyclonal anti-HSV-thymidine kinase (anti-TK; received from Dr. William Summers of Yale University, New Haven, CT) and coverslipped with Vectashield mounting medium containing DAPI nuclear stain. Confocal $z$-stack images $(1 \mu \mathrm{m}$ interval) were collected at $40 \times$ on a Leica SP8 confocal microscopy system using a resonant scanner. Images were analyzed using maximum projection images of each collected microscope field using Leica software to mark PDGFR $\alpha^{+}$cells with the TK channel hidden. Then, with the TK channel revealed, the PDGFR $\alpha^{+}$cells were scored for the presence of TK. If the colocalization of PDGFR $\alpha$ and TK in 
any cell was unclear, then orthogonal sections were used to examine the cell in each slice of the $z$-stack. Wild-type sections processed in parallel contained no TK immunolabeling.

Ganciclovir treatment. In addition to CNS cells, visceral organs and vascular mural cells express NG2. Therefore, GCV must be delivered directly into the CNS to avoid lethal systemic effects. GCV must be delivered continually (vs daily injections) because $\mathrm{NG}^{+}$cells that proliferate outside of the GCV half-life ( $\sim 4 \mathrm{~h})$ would rapidly replace lost cells. Therefore, GCV was delivered at a rate of $50 \mathrm{mg} / \mathrm{kg} / \mathrm{d}$ (dissolved in physiological saline) via Alzet minipumps (models 1002 or 1007D), which were connected to a plastic catheter and $26 \mathrm{Ga}$ delivery needle $(2.5 \mathrm{~mm}$ deep). Pumps were assembled according to manufacturer's instructions and primed overnight at $37^{\circ} \mathrm{C}$ in physiological saline before implantation. To assess potential side effects of transgenic Tk expression or GCV delivery, control groups included NG2-Tk mice receiving saline $(\mathrm{Tg}+\mathrm{Sal})$ and wild-type BL6 mice receiving GCV (WT+GCV). Groups and time points are described in Table 1.

SCI. All surgical and postoperative care procedures were performed in accordance with The Ohio State University Institutional Animal Care and Use Committee. On day 0, 12-week-old mice (30\% male, $70 \%$ female) were anesthetized with a ketamine/xylazine mixture (120 and $10 \mathrm{mg} / \mathrm{kg}$, i.p., respectively) and the spinal cord exposed at the C5 vertebral level via a single-level laminectomy. A $0.6-\mathrm{mm}$-diameter probe (smaller than a standard midline contusion probe) directed perpendicular to the dorsal right side of the spinal cord was used to create a unilateral contusion (60 kDyne force) using the Infinite Horizons device (Precision Instruments). The muscles overlying the spinal cord were sutured and the incision closed with wound clips. In addition to the mice used in GCV studies, 20 adult female wild-type mice received comparable unilateral SCIs and were randomly grouped into different survival time points for time course analyses; four uninjured wild-type mice served as naive controls. See Table 1 for all time points and group sizes.

The C5 unilateral contusion model was selected after initial pilot studies using a T9 midline contusion showed no changes in lesion morphology after GCV delivery, whereas C5 injured animals had significant alterations in the lesion environment (data not shown). This is likely due to differences in recombination efficiency between cervical ( $\sim 41 \%)$ versus thoracic $(\sim 16 \%)$ spinal regions (see Results for more details).

Intracerebroventricular cannulation and pump implantation. Immediately after receiving a SCI, mice were randomly assigned to treatment groups. Mice were placed in a stereotaxic head frame and their skulls were exposed. A hole through the skull was created using a 26 Ga needle at the coordinates $-0.7 \mathrm{~mm}$ posterior and $-1.2 \mathrm{~mm}$ lateral from bregma (coordinates of right lateral ventricle in mouse). Guide cannulas of assembled and primed minipumps were inserted through the hole into the brain at a depth of $2.5 \mathrm{~mm}$ ventral and the minipumps were placed into a subdermal pocket created on the upper back using a sterile cottontipped applicator to separate the skin and muscle. The skin behind the ears was closed using surgical clips and the exposed skull and catheter tip were covered with Ortho-Jet fast-drying acrylic resin (Lang Dental, catalog \#B1323). Animals were given $2 \mathrm{ml}$ of saline and placed in warm recovery cages. Postsurgical care included $5 \mathrm{~d}$ treatment with antibiotics (gentomicin, $5 \mathrm{mg} / \mathrm{kg}$ ) and daily saline $(2 \mathrm{ml})$ to maintain hydration, along with twice-a-day manual bladder expression until spontaneous voiding returned. Mice were regularly weighed to assess changes in body weight until they were killed at $7 \mathrm{dpi}(n=6 \mathrm{Tg}+\mathrm{Sal} ; n=7 \mathrm{Tg}+\mathrm{GCV}), 11$ dpi $(n=5 \mathrm{Tg}+\mathrm{Sal} ; n=5 \mathrm{Tg}+\mathrm{GCV} ; n=4 \mathrm{WT}+\mathrm{GCV})$, or $21 \mathrm{dpi}(n=8$ $\mathrm{Tg}+\mathrm{Sal} ; n=8 \mathrm{Tg}+\mathrm{GCV}$ ). The $7 \mathrm{~d}$ and $21 \mathrm{~d}$ groups consist of 2 replicate studies in which identical results were obtained. A total of 5 mice were lost or killed early and not included in analyses: $1 \mathrm{Tg}$ mouse died during SCI surgery; $1 \mathrm{Tg}+$ Sal mouse was removed early at 8 dpi due to a prolapsed penis; $1 \mathrm{Tg}+\mathrm{GCV}$ mouse was removed early at $10 \mathrm{~d}$ i from excess weight loss and dehydration; $1 \mathrm{Tg}+\mathrm{GCV}$ was found dead at $11 \mathrm{dpi}$ from intestinal issues; and $1 \mathrm{Tg}+\mathrm{GCV}$ mouse was removed early at 12 dpi due to general declining health and lethargy.

Pump removal. Mice surviving longer than 2 weeks after injury were reanesthetized at 14 dpi using isofluorane and the dorsal incision was reopened to expose the base of the skull. Pumps were removed from their subdermal pocket and cut from their catheters. The exposed end of the plastic catheter was melted using a cautery pen and sealed shut using a hemostat for several seconds. Intraventricular cannulas remained in place. The skin was closed with surgical clips.

Stepping analysis. To assess changes in forelimb step length, mice from the 21 dpi groups, 11 dpi WT + GCV mice, and naive wild-type mice were videotaped walking across a custom-made walkway. This setup consisted of a clear plastic platform enclosed by two clear plastic walls. A mirror was placed at an angle below the platform such that the video camera could capture both a side view and a view of paw placement from below in the same frame. Each mouse was recorded performing at least 3 passes of at least 5 consecutive steps at a consistent pace per recording session $(0$, 7,11 , and $21 \mathrm{dpi}$, when applicable). An observer blinded to group measured right and left forelimb step lengths in each pass, which were used to derive average step length per side for each mouse. Data were analyzed using a 2-way repeated-measures ANOVA where significance was reported when $p<0.05$.

Perfusion and tissue processing. Mice were deeply anesthetized with ketamine and xylazine $(1.5 \times$ surgery dose above $)$ and perfused transcardially with PBS, followed by $4 \%$ paraformaldehyde (PFA) in PBS. Spinal cords and brains were removed, postfixed for $2 \mathrm{~h}$ at $4^{\circ} \mathrm{C}$ in $4 \% \mathrm{PFA}$, and placed in $0.2 \mathrm{M} \mathrm{PB}$ overnight. The following day, tissue was cryoprotected in $30 \%$ sucrose dissolved in $0.1 \mathrm{M}$ PBS at $4^{\circ} \mathrm{C}$ for $48 \mathrm{~h}$. For tissue embedding, spinal cords and brains were frozen on dry ice and spinal cords were cut into $1 \mathrm{~cm}$ blocks centered on the lesion site. After submersion in optimum cutting temperature compound (Electron Microscopy Sciences), blocks were frozen and cross-sections were cut at $10 \mu \mathrm{m}$ on a cryostat and mounted serially onto slides. Tissue was stored at $-20^{\circ} \mathrm{C}$ until use.

Immunohistochemistry. Sections were rinsed in $0.1 \mathrm{M}$ PBS and blocked for nonspecific antigen binding using 4\% BSA/0.1\% Triton X-100/PBS $\left(\mathrm{BP}^{+}\right)$or $4 \% \mathrm{BSA} / 0.3 \%$ Triton-100/PBS $\left(\mathrm{BP}^{+}\right)$for $1 \mathrm{~h}$. Next, sections were incubated in primary antibody overnight at $4^{\circ} \mathrm{C}$. Sections were rinsed and treated with biotinylated antiserum (1:800-1:2000 in $\mathrm{BP}^{+}$; Vector Laboratories) for $1 \mathrm{~h}$ at room temperature. After rinsing, endogenous peroxidase activity was quenched using a 4:1 solution of methanol/ $30 \%$ hydrogen peroxide for $15 \mathrm{~min}$ in the dark. Sections were then treated with Elite avidin-biotin enzyme complex (ABC; Vector Laboratories) for $1 \mathrm{~h}$. Visualization of labeling was achieved using DAB or SG substrates (Vector Laboratories). For some sections, cell nuclei were visualized by counterstaining with Neutral Red for $10 \mathrm{~min}$. Sections were rinsed, dehydrated, and coverslipped with Permount (Fisher Scientific). See Table 2 for details on primary antibodies.

Immunofluorescence Sections were rinsed in $0.1 \mathrm{M}$ PBS and blocked for nonspecific antigen binding using $\mathrm{BP}^{+}$or $\mathrm{BP}^{+}$for $1 \mathrm{~h}$. Next, sections were incubated in primary antibodies overnight at $4^{\circ} \mathrm{C}$. Sections were rinsed and incubated with Alexa Fluor secondary antibodies (1:500-1:1000; Invitrogen) for $1 \mathrm{~h}$. After rinses, sections were incubated with Draq5 (1:3000; Biostatus, catalog \#DR50050 RRID:AB_2314341) for 10-15 min to label cell nuclei. Slides were coverslipped with ImmuMount (Thermo Scientific). See Table 2 for a list of primary antibodies with RRID information. Immunofluorescent labeling was analyzed by laser scanning confocal microscopy (Leica, TCS SP8) and LAS X software.

Red blood cell labeling To visualize red blood cells, tissue sections were rinsed in $0.1 \mathrm{M}$ PBS and incubated with DAB for $10 \mathrm{~min}$ without prior peroxide quenching.

Cell counts. A Zeiss Axioshop 2 Plus microscope with a Sony 970 threechip color camera was used to analyze tissue immunolabeled by immunohistochemistry. Cells double-labeled for NG2 or PDGFR $\beta$ and Ki67 were counted manually in ipsilateral spinal cords at high power $(40 \times)$ in the epicenter and 2 consecutive sections rostral and caudal for each ani$\mathrm{mal}(-0.3 \mathrm{~mm}$ to $+0.3 \mathrm{~mm})$ ipsilateral to the injury. Total counts are reported as a summation of the five consecutive sections. Cells were categorized by morphology (pericyte morphology or branched morphology) and location in the cord (spared tissue, lesion border, within lesion). Cell counts are expressed as cells per square millimeter. Cells were only included in the analyses if they possessed a clear $\mathrm{Ki}^{+} 7^{+}$nucleus that was at least $75 \%$ surrounded by NG2 or PDGFR $\beta$ labeling. A cell was classified as a pericyte if it demonstrated a crescent morphology and appeared to circumscribe a blood vessel. All other double-positive cells were classified as "branched" if they possessed at least one ex- 
Table 2. Primary antibodies used, their concentration, host species, company of origin, and RRID information

\begin{tabular}{|c|c|c|c|c|c|}
\hline Primary antibody: specificity & Concentration & Host species & Vendor & Catalog no. & RRID \\
\hline CD31: blood vessels & $1 / 2000$ & Rat & BD Pharmingen & 551262 & RRID:AB_398497 \\
\hline CD68: macrophages & $1 / 500$ & Rat & Serotec (now known as Bio-Rad) & MCA1957 & RRID:AB_322219 \\
\hline GFAP: astrocytes & $1 / 10,000$ & Rabbit & Dako & N1506 & RRID:AB_10013482 \\
\hline GST $\pi$ : oligodendrocytes & $1 / 1500$ & Rabbit & Biorbyt & orb18037 & RRID:AB_10778283 \\
\hline Ki67: proliferating cells & $1 / 200$ & Rat & Dako & M7248 & RRID:AB_2250503 \\
\hline Laminin: ECM molecule & $1 / 5000$ & Rabbit & Sigma-Aldrich & L9393 & RRID:AB_477163 \\
\hline Mac1: Cd11b, microglia/macrophages & $1 / 200$ & Rat & DSHB & M1/70.15.11.50.2 & RRID:AB_2234066 \\
\hline NeuN: neurons & $1 / 10,000$ & Rabbit & Abcam & ab177487 & RRID:AB_2532109 \\
\hline Neurofilament: axons & $1 / 1000$ & Chicken & Aves Labs & NF-H & RRID:AB_2313552 \\
\hline NG2: pericytes and oligodendrocyte progenitors & $1 / 200-1 / 1000$ & Rabbit & Millipore & AB5320 & RRID:AB_11213678 \\
\hline PDGFR $\beta$ : pericytes, fibroblasts & $1 / 500$ & Rabbit & Abcam & ab32570 & RRID:AB_777165 \\
\hline
\end{tabular}

tending process. Care was taken to avoid counting $\mathrm{NG}^{+}$macrophages, which are easily distinguished by their round morphology and space between the nucleus and membrane (Tripathi and McTigue, 2007). Data were analyzed using a one-way ANOVA and post hoc Bonferroni multiple-comparisons test.

Quantification of $\mathrm{NG}^{+}$cells wrapping $\mathrm{CD} 31^{+}$blood vessels was conducted by immunofluorescent labeling and analyzed by laser scanning confocal microscopy (Leica TCS SP8) and LAS X software. $z$-stacks at $40 \times$ magnification were collected for the entire ipsilateral spinal cord and three nonoverlapping sample boxes were placed randomly within the lesion, and evenly and systematically along the lesion border at the injury epicenter. Maximal projection images were used to quantify $\mathrm{NG}^{+}$profiles containing Draq $5^{+}$nuclei that completely encircled a CD $31^{+}$blood vessel and did not extend additional processes beyond the blood vessel area. Data were analyzed by two-way repeated-measures ANOVA and post hoc Bonferroni multiple-comparisons test.

In NG2-Tk tissue, $\mathrm{NG} 2^{+}$cells were quantified at the injury epicenter using Neutral Red counterstain to identify cell bodies. Cells were categorized by morphology (pericytes or branched) as described above. Three sample boxes at $40 \times$ magnification were evenly and systematically placed along the lesion border and also just outside of the lesion border in spared tissue. Cell counts from these sample boxes were summed and expressed as cells per square millimeter. Lesion border GST $\pi^{+}$oligodendrocytes were quantified in a similar manner. A two-way repeated-measures ANOVA and post hoc Bonferroni multiple-comparisons test was used to analyze branched and pericyte-shaped $\mathrm{NG}_{2}{ }^{+}$cells; OL counts were analyzed using a two-way ANOVA and post hoc Bonferroni multiple-comparisons test.

Neurons $\left(\mathrm{NeuN}^{+}\right.$cells) were quantified using the automated cell counter function within MCID image analysis software (InterFocus Imaging; RRID:SCR_014278). Soma size and staining intensity thresholds were defined and cells were quantified separately in dorsal (laminae I-IV), middle (between laminae IV and central canal), and ventral (below the central canal) gray matter. Data were analyzed with a two-tailed Student's $t$ test.

Lesion and spared tissue area. Lesion area and ipsilateral spared white and gray matter in NG2-Tk and wild-type mice were assessed by staining myelin with Eriochrome cyanine (EC) and immunolabeling for neurofilament (NF), as described previously (Schonberg et al., 2007). Digitized images of EC/NF-labeled cross-sections were captured using MCID image analysis software. The lesion area at the epicenter, defined as the region with the least ipsilateral intact myelin immunoreactivity, was outlined digitally and its target area was measured and expressed in square millimeters. Spared tissue area was calculated as the ipsilateral cross-sectional area minus the lesion area. Data were analyzed using a two-way ANOVA and post hoc Bonferroni multiplecomparisons test.

Intralesion quantification. To quantify the intralesion area of immunoreactivity for NG2, NF, GFAP, Mac1, CD31, laminin, and PDGFR $\beta$ at the epicenter, a template of the lesion area was generated from an adjacent section stained by EC/NF and placed over the corresponding image. Using MCID, a minimum signal threshold for each label was determined and the total amount of intralesion labeling was measured. The proportional area of positive labeling was calculated by dividing total target area by lesion area and expressed as a percentage. This same method was used to quantify the proportional area of CD31 labeling in spared gray and white matter. Data were analyzed using a two-way ANOVA and post hoc Bonferroni multiple-comparisons test.

Lesion border and extralesion quantification. The amount of lesion border NG2, GFAP, and Mac1 labeling was assessed by thresholding similar to intralesion analyses. For NG2 and GFAP, corresponding EC/NFlabeled sections were used as a guide to determine the exact lesion borders and three sample boxes were placed equidistant along the lesion border (one dorsal, one ventral, one middle) for each stain at the epicenter. For NG2 and Mac1, sample boxes were square, measuring 0.002 $\mathrm{mm}^{2}$. For GFAP, sample boxes were rectangular, measuring $0.003 \mathrm{~mm}^{2}$. For Mac1, the three samples boxes were placed in spared tissue; one box was placed just to the right of the central canal, one was placed above in gray matter, and the third was placed at an equidistant below. The total amount of labeling within sample boxes was measured and summed for each section to determine an overall percentage of labeling outside of the lesion. All data were analyzed using a two-way ANOVA and post hoc Bonferroni multiplecomparisons test except CD31 data, which were analyzed using two-way repeated-measures ANOVA and Bonferroni post hoc test.

Data analyses. An investigator blinded to group assignment performed all quantification. Significance is reported when $p<0.05$. Specific statistical analyses are given for each data section below. Depending on the statistical test, $p^{-}, q^{-}$, or $t$-values are reported where appropriate. Plates were constructed using Adobe Photoshop (RRID:SCR_014199) and all images within a plate were adjusted equally to improve contrast when needed.

\section{Results}

Differential NG2 ${ }^{+}$glia and pericyte proliferation over the first 2 weeks after $\mathrm{C} 5$ unilateral contusion in wild-type mice $\mathrm{NG}_{2}{ }^{+}$glia are known to proliferate after SCI and accumulate in the glial scar, where they interdigitate with astrocytes (Fig. 1A). $\mathrm{NG}^{+}$pericyte proliferation has not been quantified after SCI to our knowledge, but pericytes likely divide because new pericytes would be needed for post-SCI angiogenesis; therefore, both dividing $\mathrm{NG}_{2}{ }^{+}$cell populations could be ablated in our study. To determine when proliferating $\mathrm{NG}^{+}$glia and pericytes would be vulnerable to ganciclovir-induced death in our model, a time course study after C5 unilateral contusion in wild-type mice was performed. Spinal cord cross-sections from the injury site were doublelabeled for NG2 and Ki67 (expressed by dividing cells) in naive and $1,3,7,11$, and 14 dpi tissue, and the number of NG2 ${ }^{+}$cells expressing Ki67 ipsilateral to the injury was quantified at each time point. Dividing NG2 ${ }^{+}$cells were categorized as glia or pericytes based on branched versus crescent-shaped morphology, respectively. Examples of both phenotypes are shown in Figure $1 B$.

As expected, the number dividing $\mathrm{NG}^{+}{ }^{+}$glia robustly increased ipsilateral to the injury at 3, 7, and 11 dpi compared with naive, with peak levels of $\sim 22$ cells $/ \mathrm{mm}^{2}$ at $7 \mathrm{dpi}$ (Fig. $1 C$ ). The vast majority of proliferating $\mathrm{NG}^{+}$glia were located in proximal spared tissue and 

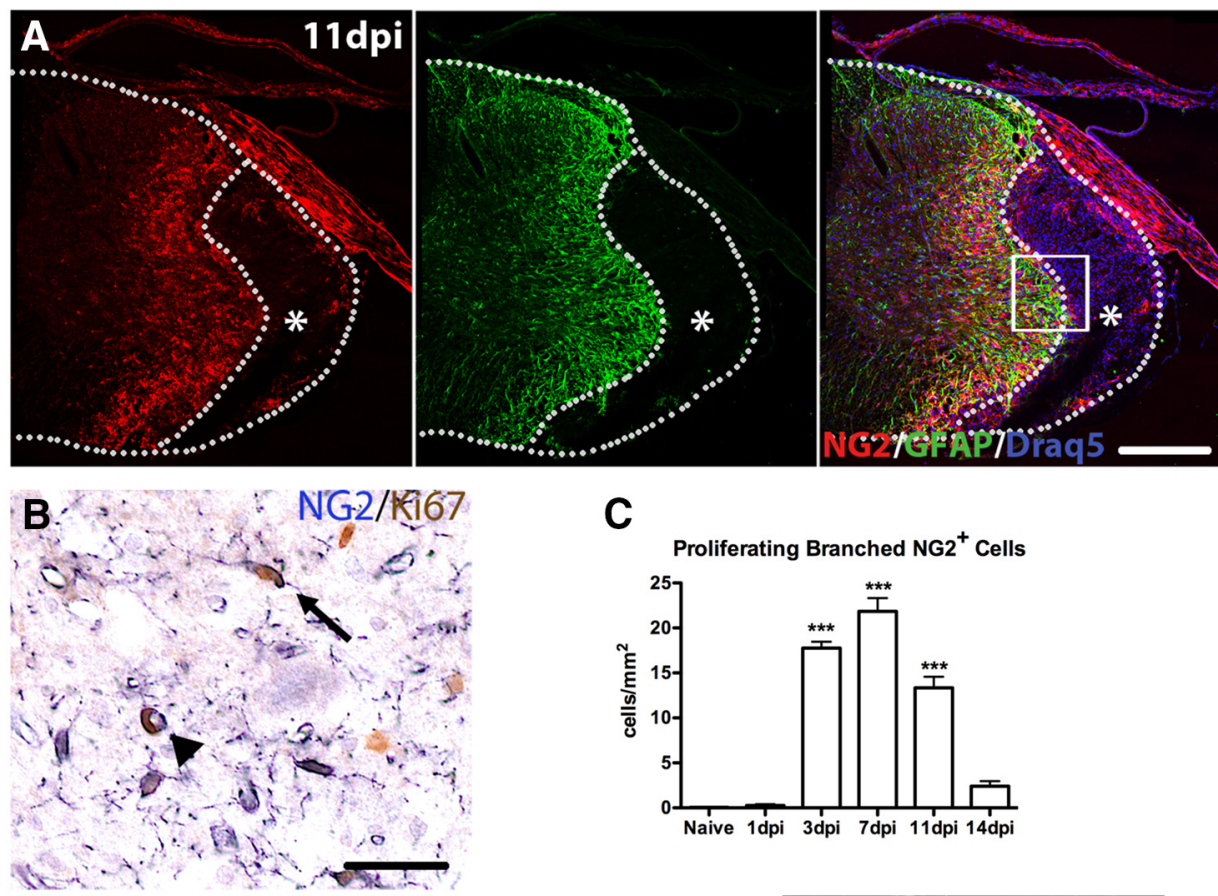

C
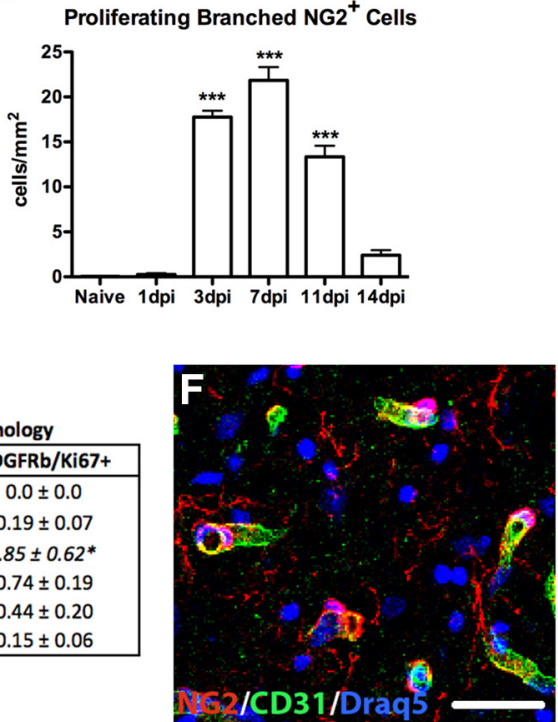

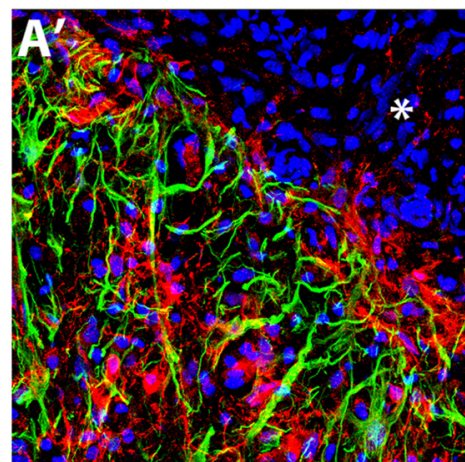

D

Proliferating Pericyte-Shaped Cells

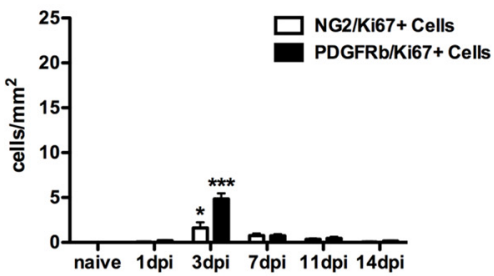

G

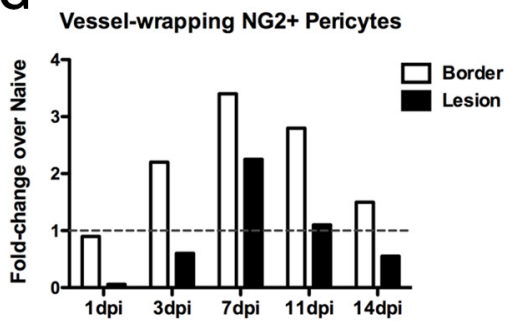

Figure 1. Proliferation of NG2 ${ }^{+}$and PDGFR $\beta^{+}$cells after $C 5$ unilateral contusion in wild-type mice. $A$, Single-channel and merged confocal images showing that NG2 and GFAP are upregulated along lesion borders, where NG2 ${ }^{+}$cells (red) and GFAP ${ }^{+}$cells (green) intermingle by 11 dpi. Nuclei are labeled by Draq 5 (blue). Asterisks denote lesion core. Boxed area in $A$ shown at higher power in $\boldsymbol{A}^{\prime}$. B , Example of a branched (black arrow) and pericyte-shaped (arrowhead) NG2/Ki67 ${ }^{+}$cell from $7 \mathrm{dpi}$ spared tissue. C, Quantification of branched NG2/Ki67 ${ }^{+}$cells/mm ${ }^{2}$ in the injured ipsilateral spinal cord; proliferation was significantly increased compared with naive tissue at 3, 7, and 11 dpi. D, Quantification of pericyte-shaped NG2/Ki67 ${ }^{+}$cells $/ \mathrm{mm}^{2}$ and PDGFR $\beta / \mathrm{Ki}{ }^{+}$ cells $/ \mathrm{mm}^{2}$ in the injured ipsilateral spinal cord. Proliferation of both populations was significantly increased at $3 \mathrm{dpi}$ compared with naive. Note that the $y$-axis is the same as in $C$ to facilitate comparisons. $\boldsymbol{E}$, Data table of cell quantification averages shown in $\boldsymbol{C}$ and $\boldsymbol{D}$. Asterisks denote values that are significantly increased from naive levels. $\boldsymbol{F}$, Confocal image of NG2 ${ }^{+}$pericytes (red) encircling $\mathrm{CD}_{3} 1^{+}$blood vessels (green) along the lesion border at $11 \mathrm{dpi}$. Nuclei are labeled by Draq5 (blue). G, Fold change in vascular-wrapping NG2 ${ }^{+}$pericytes within lesions and along lesion borders after SCI compared with naive (dotted line). Scale bars: $\boldsymbol{A}, 50 \mu \mathrm{m} ; \boldsymbol{B}, \boldsymbol{F}, 20 \mu \mathrm{m} .{ }^{*} p<0.05{ }^{* * * *} p<0.001$.

lesion border, with only a rare NG2/Ki67 cell in the frank lesion itself (0-1 cell/section). To determine whether $\mathrm{NG} 2^{+}$cells within the frank lesion were oligodendrocyte progenitors, sections were double-labeled for NG2 and Olig2, which is expressed by oligodendrocyte lineage cells. Whereas NG2/Olig2 double-labeled cells were abundant in the glial scar area, they were completely absent in the frank lesion (data not shown), revealing that dividing $\mathrm{NG}^{+}$glia accumulate in the glial scar area, but do not enter the lesion core after SCI in mice.

Compared with $\mathrm{NG}_{2}{ }^{+}$glia, $\mathrm{NG} 2{ }^{+}$pericyte proliferation peaked earlier and at a lower level. Peak proliferation of $\mathrm{NG}_{2}{ }^{+}$pericytes reached $\sim 1-2$ cells $/ \mathrm{mm}^{2}$ at 3 dpi (Fig. $1 D$ ). Only a subset of pericytes expresses NG2. Therefore, to quantify proliferation of all pericytes, adjacent sections were immunolabeled for Ki67 and $\operatorname{PDGFR} \beta$, which are expressed by all pericytes. This verified peak pericyte proliferation was at $3 \mathrm{dpi}$, with dividing PDGFR $\beta^{+}$cell numbers reaching $\sim 5$ cells $/ \mathrm{mm}^{2}$ (Fig. $1 D$ ). Therefore, $\sim 30 \%$ of dividing pericytes express NG2 at $3 \mathrm{dpi}$, which is when most would be vulnerable to GCV-induced ablation, whereas $\mathrm{NG} 2{ }^{+}$glia would be vulnerable from 3-11 dpi. Overall, the number of dividing $\mathrm{NG}^{+}$ glia outnumbered proliferating $\mathrm{NG} 2^{+}$pericytes 10 - to 30 -fold between 3 and 11 dpi. Numerical averages for each quantification are provided in Figure 1E. Compared with naive, degrees of freedom ( df) and $q$-values for each significant measurement are as follows: branched $\mathrm{NG} 2 / \mathrm{Ki} 67(\mathrm{df}=5 ; 3 \mathrm{dpi} q=15.62 ; 7 \mathrm{dpi} q=22.79 ; 11 \mathrm{dpi} q=12.88)$; pericyte NG2/Ki67 ( $\mathrm{df}=5 ; 3 \mathrm{dpi} q=8.98 ; 7 \mathrm{dpi} q=5.084$ ); pericyte PDGFR $\beta / \operatorname{Ki} 67(\mathrm{df}=5 ; 3 \mathrm{dpi} q=15.93 ; 7 \mathrm{dpi} q=5.612)$.

To confirm that cells classified as $\mathrm{NG}{ }^{+}$pericytes wrapped blood vessels and to further characterize changes in the $\mathrm{NG}^{+}$pericyte population, tissue was immunolabeled for NG2 and CD31 (PECAM-1), counterstained with Draq5, and analyzed with confocal microscopy (Fig. $1 F$ ). Quantification of NG2 ${ }^{+}$pericytes encircling $\mathrm{CD}_{3} 1^{+}$vessels revealed a complete loss in the lesions at $1 \mathrm{dpi}$, followed by a rise within lesions to $\sim 2$-fold greater than naive by 7 $\mathrm{dpi}(\mathrm{df}=5 ; q=3.264$; Fig. $1 G)$. Within lesion borders, cell numbers were unchanged at $1 \mathrm{dpi}$, but increased $>3$-fold by $7 \mathrm{dpi}$ (Fig. $1 G$ ). Therefore, peak pericyte proliferation at $3 \mathrm{~d}$ yields increased NG2 ${ }^{+}$ pericytes in lesions and spared tissue by $7 \mathrm{dpi}$. NG2 ${ }^{+}$pericytes encircling vessels subsequently decline, especially within the lesion, 
A

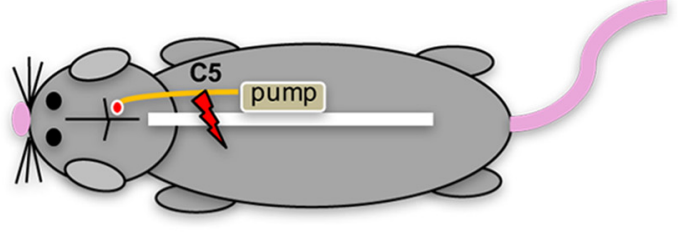

B
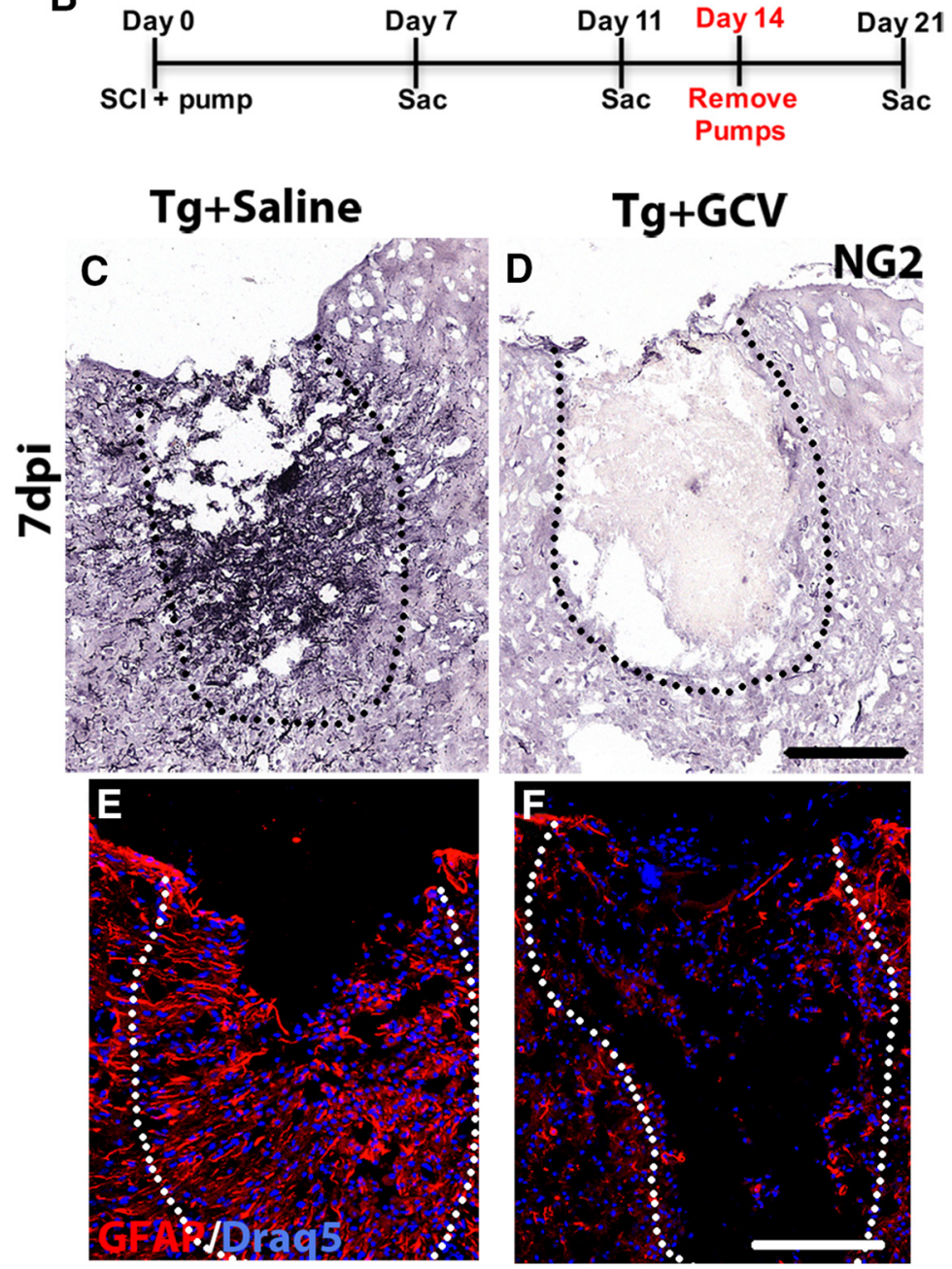

Figure 2. Experimental design and successful ablation of proliferating NG2 ${ }^{+}$cells in NG2-Tk mice after GCV infusion. $A$, Schematic of $C 5$ unilateral contusion injury and minipump implantation paradigm in mice. $\boldsymbol{B}$, Timeline of experimental design. Different cohorts of mice received continuous intraventricular GCV or saline infusion until they were killed at $7 \mathrm{~d}$ (divided into 2 replicates) or $11 \mathrm{dpi}$. A third cohort (divided into two replicates) had pumps removed at $14 \mathrm{dpi}$ and were killed 1 week later. $\mathbf{C} \boldsymbol{F}$, Intraventricular cannulation triggered transient, yet robust $\mathrm{NG}^{+}{ }^{+}$and $\mathrm{GFAP}^{+}$cell accumulation around the cannulation site in control mice; this accumulation was prevented in GCV-infused mice. Scale bars, $50 \mu \mathrm{m}(\boldsymbol{C}-\boldsymbol{F})$.

which may be due to vessel remodeling and downregulation of NG2 by pericytes after vessel formation.

\section{Quantification of TK recombination efficiency}

Immunostaining confirmed that HSV-TK was present in NG2 cells labeled with anti-PDGFR $\alpha$. TK was expressed at high levels in the cell soma, but was also visible in the proximal cell processes of many NG2 cells (data not shown). In spinal cord sections from 3 -month-old mice, an average of $22 \%$ of PDGFR $\alpha^{+}$cells expressed TK $\left(188 / 853\right.$ cells). The percentage of $\mathrm{TK}^{+}$cells was higher in anterior spinal cord compared with more posterior regions $(41 \%, 16 \%$, and $12 \%$ in the cervical, thoracic, and lumbar regions, respectively).

\section{Experimental design of NG2 ${ }^{+}$}

cell ablation

To ablate proliferating $\mathrm{NG}^{+}{ }^{+}$cells within the CNS after SCI, GCV was infused into the right lateral ventricle of NG2-Tk mice beginning immediately after a $\mathrm{C} 5$ unilateral contusion (Fig. 2A). Because most $\mathrm{NG}^{+}{ }^{+}$cells proliferated between 3 and 11 dpi, we examined GCV-infused tissue at 7 and $11 \mathrm{dpi}$. To investigate tissue response after the removal of GCV, a third group of NG2-Tk mice received GCV for $14 \mathrm{~d}$ and then survived an additional $7 \mathrm{~d}$ (without GCV) until 21 dpi (Fig. 2B). Control groups included transgenic mice infused with saline $(\mathrm{Tg}+\mathrm{Sal})$ and wild-type mice infused with GCV (WT+GCV). See Table 1 for a summary of animal numbers, experimental groups, and time points.

\section{Successful ablation of proliferating $\mathrm{NG}^{+}{ }^{+}$cells in NG2-Tk mice after GCV infusion}

To confirm that intraventricular GCV infusion into NG2-Tk mice ablates proliferating $\mathrm{NG}_{2}{ }^{+}$cells, the brains of $\mathrm{Tg}+\mathrm{GCV}$ and $\mathrm{Tg}+$ Sal mice were collected at $7 \mathrm{dpi}$ and immunolabeled for NG2 at the cannulation site. Cannulation produces mild but transient inflammation and gliosis and, as expected, NG2 cells increased in the area immediately around the cannulation site in NG2-Tk treated with vehicle $(\mathrm{Tg}+\mathrm{Sal})$ compared with adjacent tissue (Fig. $2 C$ ). In contrast, NG2-Tk mice given GCV had a near complete loss of proliferating NG2 ${ }^{+}$ cells in the area (Fig. 2D). Brain sections were also immunolabeled for astrocytes with GFAP. $\mathrm{Tg}+$ Sal tissue showed a robust accumulation of $\mathrm{GFAP}^{+}$cells at the site of cannulation (Fig. 2E), which is indicative of transient gliosis, whereas $\mathrm{Tg}+\mathrm{GCV}$ mice had visibly lower GFAP labeling in this region (Fig. 2F).

GCV infusion in NG2-Tk mice reduces spinal cord $\mathrm{NG}^{+}{ }^{+}$cells acutely after $\mathrm{SCI}$ To assess NG2 ${ }^{+}$cell responses in GCVand saline-treated mice, spinal cord crosssections were immunolabeled for NG2. At $7 \mathrm{dpi}, \mathrm{Tg}+$ Sal mice had stereotypical accumulation of $\mathrm{NG}^{+}{ }^{+}$cells around and within lesion borders (Fig. $3 A$ ). In contrast, NG2 was markedly reduced in Tg+GCV spinal cords around the lesion. Cell counts revealed a significant $\sim 40 \%$ reduction in $\mathrm{NG}^{+}$glia and an $\sim 50 \%$ reduction in pericytes in the lesion border and adjacent spared tissue in GCV-treated mice (branched $p=0.0447$; pericyte $p=0.0377$; Fig. $3 B, C)$. Within the lesions of these mice, there was a striking loss of tissue integrity (Fig. 3B), which rendered lesion size analysis unreliable.

Despite continued GCV infusion at $11 \mathrm{dpi}$, the percentage area of NG2 immunoreactivity along lesion borders was significantly increased in $\mathrm{Tg}+\mathrm{GCV}$ mice compared with controls $(\mathrm{df}=$ $2 ; q=4.532$; Fig. $3 D-F)$. These data suggest that proliferation of 
NG2 Tg+Saline

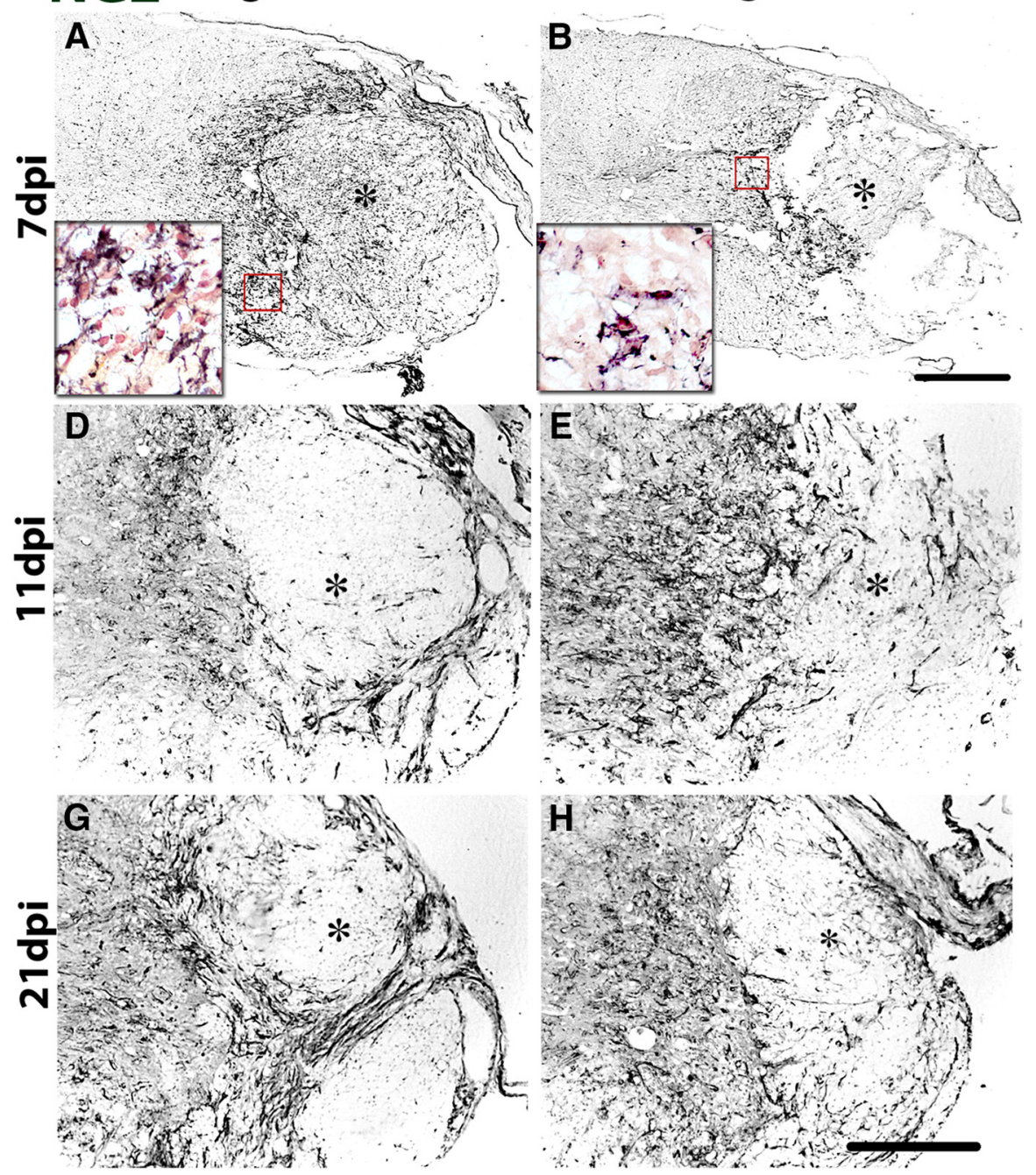

C

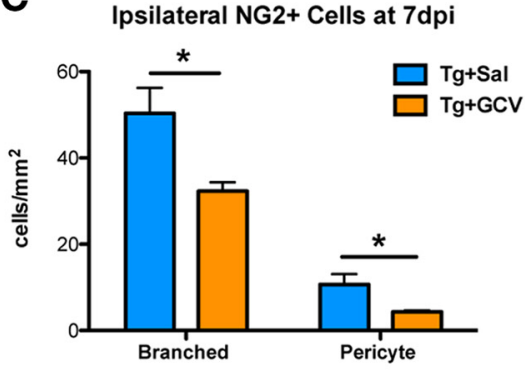

$\mathbf{F}$

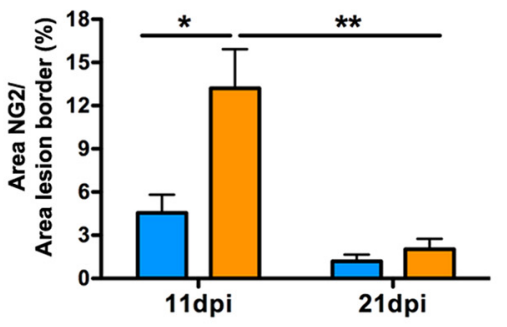

I

Lesion Border Oligodendrocytes

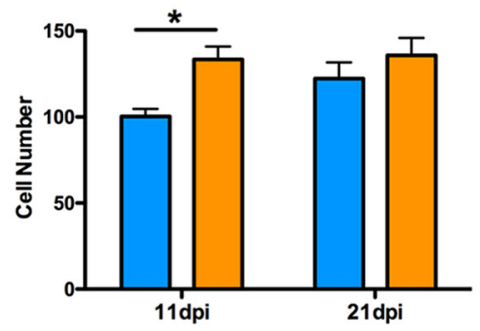

Figure 3. Changes in spinal cord NG2 expression over time after proliferating NG2 ${ }^{+}$cell ablation. $\boldsymbol{A}, \boldsymbol{B}$, Representative images of NG2/Neutral Red immunolabeling at $7 \mathrm{dpi} \mathrm{in} \mathrm{Tg}+\mathrm{Sal}$ and $\mathrm{Tg}+\mathrm{GCV}$ spinal cords. Insets show regions in red boxes at higher power. C, Quantification of NG2 ${ }^{+}$glia and NG2 ${ }^{+}$pericytes at $7 \mathrm{dpi}$ in $\mathrm{Tg}+\mathrm{Sal}$ versus Tg+GCV C5 spinal cord sections. Branched NG2 ${ }^{+}$glia were significantly reduced by $\sim 40 \%$ and NG2 ${ }^{+}$pericytes were significantly reduced by $\sim 50 \%$ in $\mathrm{Tg}+\mathrm{GCV}$ mice compared with Tg $+\mathrm{Sal}$ mice. $\boldsymbol{D}, \boldsymbol{E}$, Representative images of NG2 immunolabeling at $11 \mathrm{dpi}$ in $\mathrm{Tg}+\mathrm{Sal}$ and $\mathrm{Tg}+\mathrm{GCV}$ spinal cords. $\boldsymbol{F}$, Percentage area of NG2 immunoreactivity in the lesion border of Tg $+\mathrm{GCV}$ mice was significantly increased compared with control mice at $11 \mathrm{dpi}$, then decreased significantly to control levels by $21 \mathrm{dpi}, \boldsymbol{G}, \boldsymbol{H}$, Representative images of NG2 immunolabeling at $21 \mathrm{dpi}$ in $\mathrm{Tg}+$ Sal and Tg+GCV spinal cords. I, Oligodendrocytes immunolabeled for GST $\pi$ in 11 and 21 dpi tissue were quantified in lesion borders. At $11 \mathrm{dpi}, \mathrm{Tg}+\mathrm{GCV}$ lesion borders had significantly more oligodendrocytes compared with $\mathrm{Tg}+$ Sal. Asterisks in images indicate lesions. Scale bars: $\boldsymbol{A}, \boldsymbol{B}, 100 \mu \mathrm{m} ; \boldsymbol{D}-\boldsymbol{H}, 50 \mu \mathrm{m} .{ }^{*} p<0.05 ;{ }^{* *} p<0.01$.

the $\sim 60 \%$ of nonrecombined $\mathrm{NG}^{+}$cells (which would not be susceptible to GCV) likely compensated for the earlier loss of dividing $\mathrm{NG} 2{ }^{+}$cells.

A separate group of NG2-Tk mice received GCV or saline for $14 \mathrm{dpi}$ and then survived an additional week to $21 \mathrm{dpi}$. By this time, NG2 in the glial scar/lesion border area had declined significantly compared with $11 \mathrm{dpi}$ and was comparable to control levels (Fig. $3 F$ ). However, the pattern of NG2 expression within the lesions was different. $\mathrm{Tg}+$ Sal spinal cords had thick $\mathrm{NG}_{2}{ }^{+}$bands adjacent to the glial scar border and traversing the fibrotic scars, which were completely absent in $\mathrm{Tg}+\mathrm{GCV}$ tissue. In these sections, $\mathrm{NG} 2^{+}$cells were more diffuse and evenly distributed and did not form thick bands throughout the fibrotic lesion (Fig. 3G,H; see Fig. 11 for additional examples). Therefore, the signals regulating $\mathrm{NG}^{+}$cell distribution and accumulation must change between 11 and 21 dpi.
Because dividing $\mathrm{NG}_{2}{ }^{+}$cells produce new oligodendrocytes after injury, oligodendrocyte numbers may have been altered by $\mathrm{NG}^{+}$cell ablation. To investigate this, oligodendrocytes in 11 and 21 dpi tissue were immunolabeled with anti-GST $\pi$ antibody and the cells quantified in lesion borders, the typical area of greatest new oligodendrocyte accumulation after SCI (Tripathi and McTigue, 2007). Similar to increased NG2 expression in lesion borders at $11 \mathrm{dpi}$, the number of GST $\pi^{+}$oligodendrocytes in this region was significantly higher in Tg+GCV tissue at $11 \mathrm{dpi}$ compared with $\mathrm{Tg}+$ Sal tissue $(\mathrm{df}=1 ; t=2.871)$. By $21 \mathrm{dpi}$, oligodendrocyte numbers had risen in controls to reach numbers comparable to the Tg+GCV group (Fig. 3I). Therefore, this model effectively reduced proliferating $\mathrm{NG}^{+}$cells in the first week after injury. Early loss of proliferating $\mathrm{NG}^{+}$glia and pericytes resulted in delayed $\mathrm{NG}_{2}{ }^{+}$cell accumulation and a chronic change in the distribution of these cells within spared and lesioned tissue. 

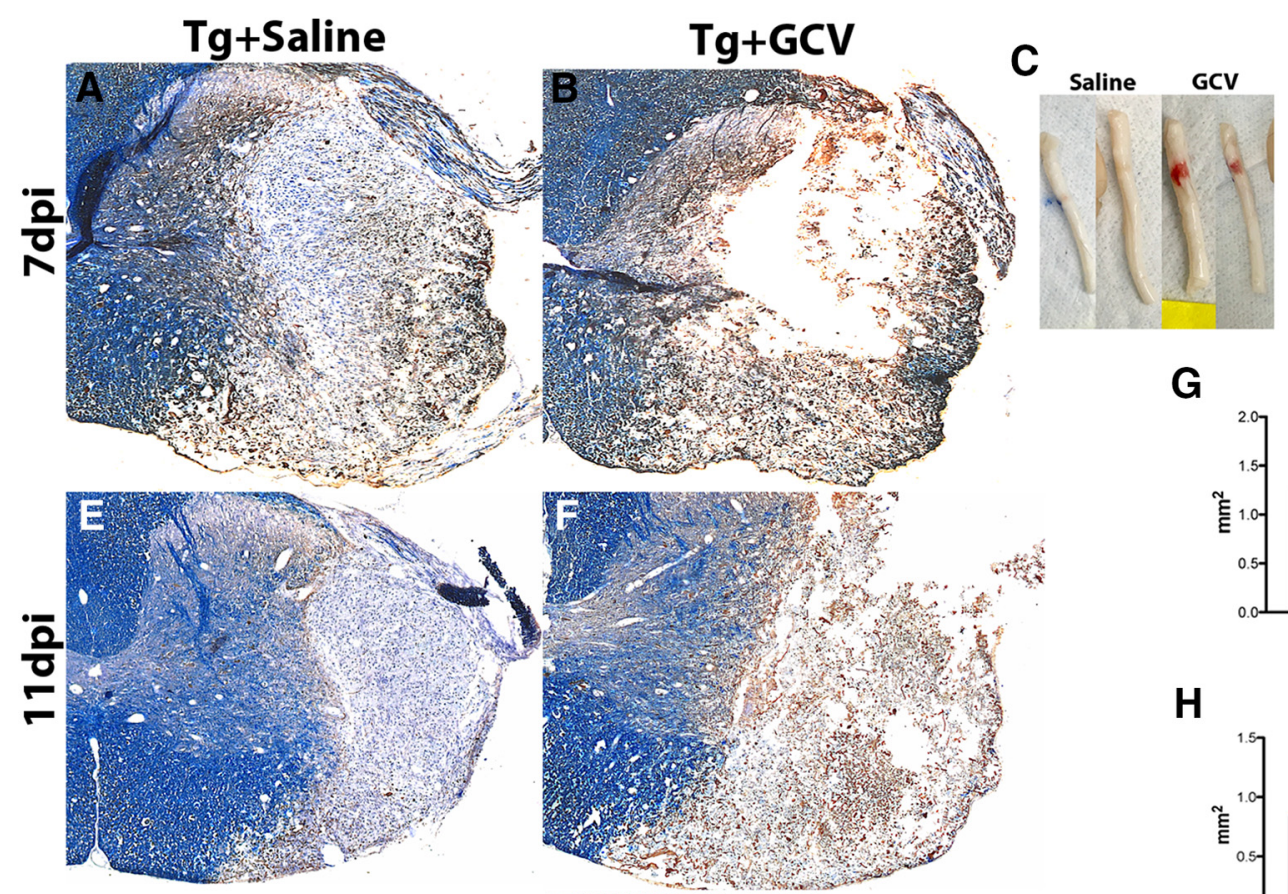

D

\section{G}

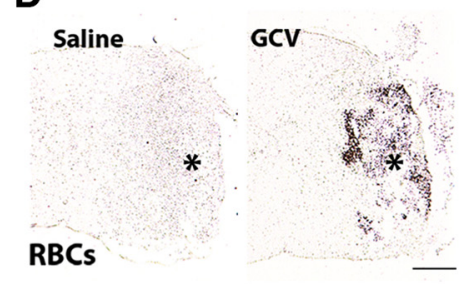

\section{Total Ipsilateral Area}

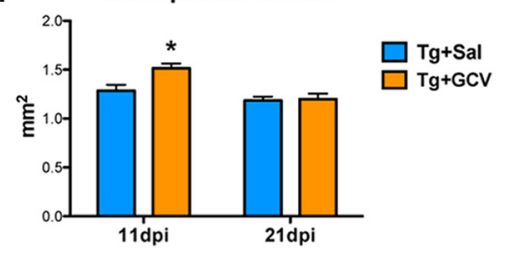

H
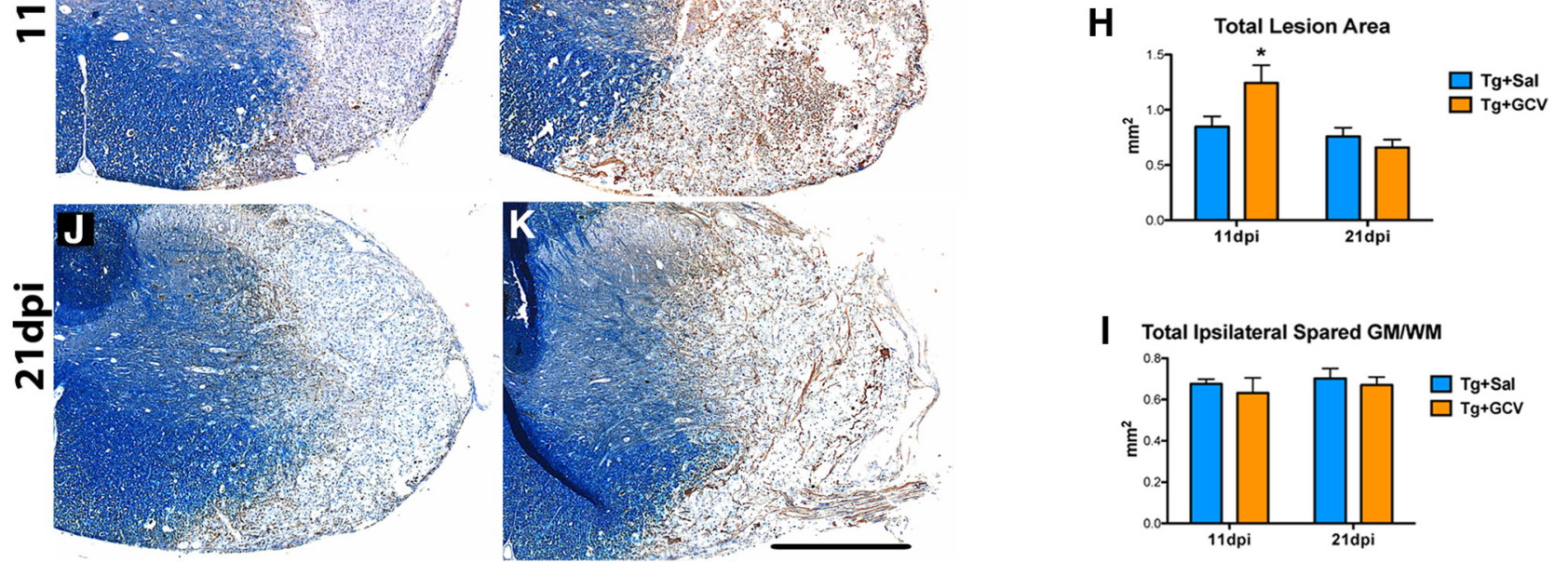

Figure 4. Ablating proliferating NG2 ${ }^{+}$cells after $\mathrm{SCl}$ causes intraspinal edema, lesion swelling, and prolonged hemorrhage. $\boldsymbol{A}, \boldsymbol{B}$, Representative images of myelin (blue) and axon (brown) labeling at $7 \mathrm{dpi} \mathrm{in} \mathrm{Tg}+\mathrm{Sal}$ and $\mathrm{Tg}+\mathrm{GCV}$ spinal cords reveal greater tissue loss in $\mathrm{Tg}+\mathrm{GCV}$ lesions. C, At $7 \mathrm{dpi}$, spinal cords of Tg $+\mathrm{GCV}$ mice were visibly bloody in the injury site; blood was absent in $\mathrm{Tg}+$ Sal mouse cords. $\boldsymbol{D}$, Infiltrating RBCs were cleared by $7 \mathrm{dpi}$ in $\mathrm{Tg}+\mathrm{Sal}$ mice, but large numbers of RBCs remained in the lesions of $\mathrm{Tg}+\mathrm{GCV}$ mice. Lesions in images are indicated by asterisks. $\boldsymbol{E}, \boldsymbol{F}$, Representative images of myelin/axon labeling at $11 \mathrm{dpi}$ in $\mathrm{Tg}+\mathrm{Sal}$ and $\mathrm{Tg}+\mathrm{GCV}$ spinal cords. G-I, Quantification of ipsilateral cross-section area $(\boldsymbol{G})$, lesion area $(\boldsymbol{H})$, and spared tissue area (I) in control and $\mathrm{Tg}+\mathrm{GCV}$ mice at 11 and $21 \mathrm{dpi}$. The total ipsilateral and lesion areas were significantly larger in $\mathrm{Tg}+\mathrm{GCV}$ mice at 11 dpi compared with controls. J, $\boldsymbol{K}$, Representative images of myelin/axon labeling at $21 \mathrm{dpi} \mathrm{in} \mathrm{Tg}+\mathrm{Sal}$ and $\mathrm{Tg}+\mathrm{GCV}$ spinal cords. Scale bar, $50 \mu \mathrm{m} .{ }^{*} p<0.05$.

\section{Ablating proliferating NG ${ }^{+}$cells acutely after SCI causes intraspinal edema, lesion swelling, and prolonged hemorrhage}

Lesion morphology was assessed in epicenter sections labeled for myelin (EC) and NF. At $7 \mathrm{dpi}$, Tg + Sal sections had stereotypical tissue and lesion border morphology (Fig. 4A). In contrast, $\mathrm{Tg}+\mathrm{GCV}$ spinal cords showed a profound lack of tissue integrity in and around lesions, with large edema-like holes and enlarged lesion cavities that were filled with debris (Fig. $4 B$ ).

Upon dissection at $7 \mathrm{dpi}$, the epicenters of Tg+GCV cords were visibly red compared with control spinal cords, suggesting sustained hemorrhage in this tissue (Fig. 4C). This was confirmed by staining for red blood cells (RBCs) with DAB, which showed that lesions of $\mathrm{Tg}+$ Sal mice contained no RBCs at $7 \mathrm{dpi}$, as expected (Fig. 4D). In contrast, RBCs filled lesions of Tg+GCV mice at $7 \mathrm{dpi}$, indicating that killing dividing NG2 ${ }^{+}$cells over the first 7 dpi led to prolonged bleeding and/or delayed clearance of RBCs (Fig. 4D).

At $11 \mathrm{dpi}$, control $\mathrm{Tg}+$ Sal tissue was similar to $7 \mathrm{dpi}$, with well defined lesion borders and lack of myelin and axons in the lesions (Fig. 4E). Tissue from control wild-type mice treated with GCV $(\mathrm{WT}+\mathrm{GCV})$ was indistinguishable from $\mathrm{Tg}+$ Sal tissue, demon- strating that GCV by itself was not responsible for the altered phenotype of Tg+GCV mice; therefore, for the remainder of this study, Tg + Sal and WT + GCV will be collectively referred to as "control mice" unless otherwise noted (see Fig. 11 for images of $\mathrm{WT}+\mathrm{GCV}$ tissue).

At $11 \mathrm{dpi}$, Tg + GCV lesions still displayed reduced integrity, swelling, and debris, although less than at $7 \mathrm{dpi}$ (Fig. $4 F$ ). No blood was present in the lesions at this time, suggesting that hemorrhage had stopped and RBCs were cleared between 7 and 11 dpi. Quantification revealed significantly larger ipsilateral area in $\mathrm{Tg}+\mathrm{GCV}$ epicenters compared with controls at $11 \mathrm{dpi}(\mathrm{df}=1$; $t=2.605$; Fig. $4 G$ ). The increased ipsilateral tissue area was due to significantly increased lesion size in $\mathrm{Tg}+\mathrm{GCV}$ mice $(\mathrm{df}=1 ; t=$ 3.113 ), with no difference in spared gray or white matter area compared with controls at 11 dpi (Fig. $4 H, I$ ) or in the number of neurons (data not shown). Therefore, loss of proliferating NG2 ${ }^{+}$ cells caused intralesion swelling, but not lesion expansion into intact spared tissue.

To examine long-term changes in SCI lesions after acute loss of dividing $\mathrm{NG}^{+}{ }^{+}$cells, tissue from mice receiving vehicle or GCV for $14 \mathrm{dpi}$ and then surviving to $21 \mathrm{dpi}$ was examined. In this group, lesion morphology in control mice was similar to 11 dpi (Fig. $4 J$ ). In 

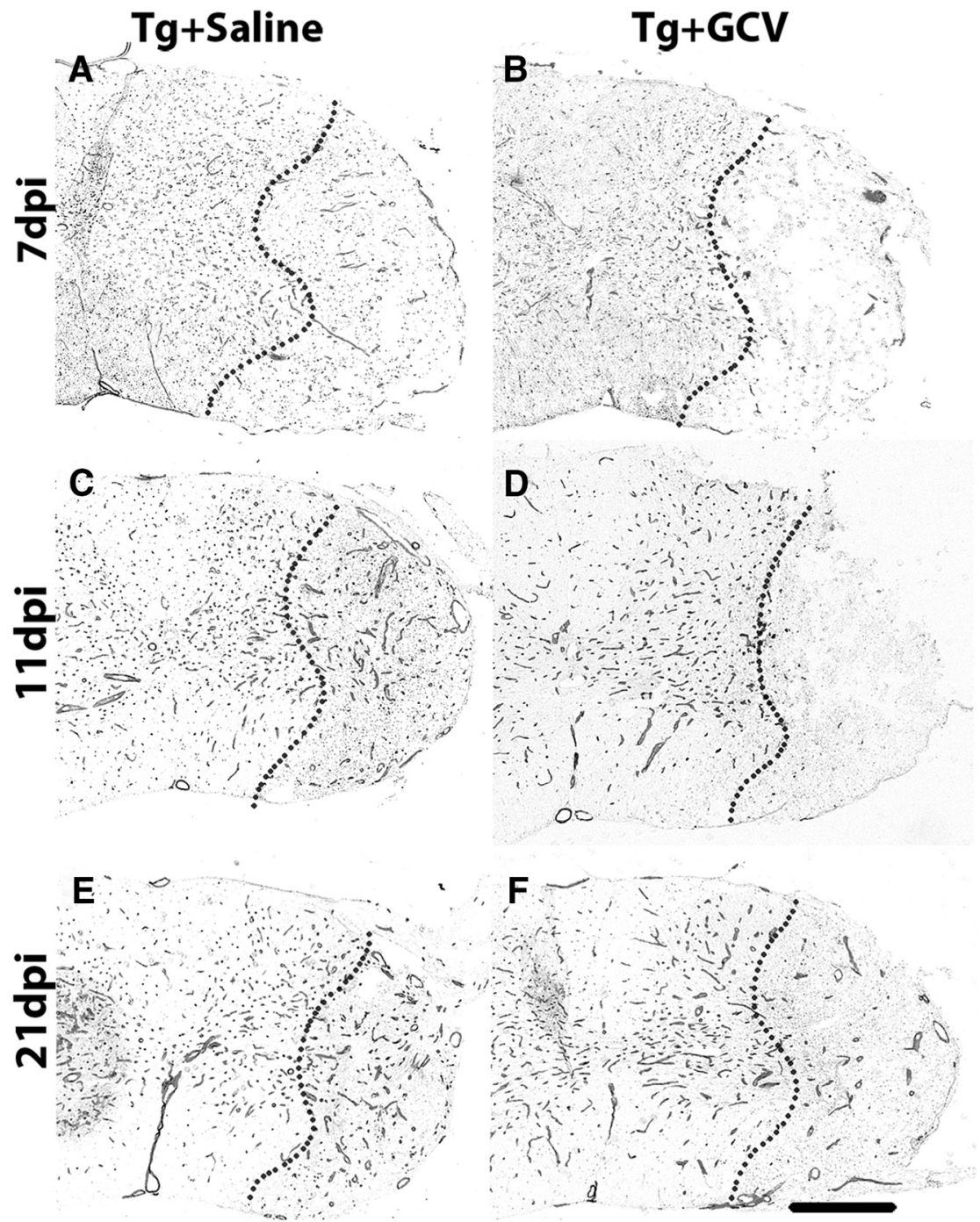

\section{Tg+GCV}

B.
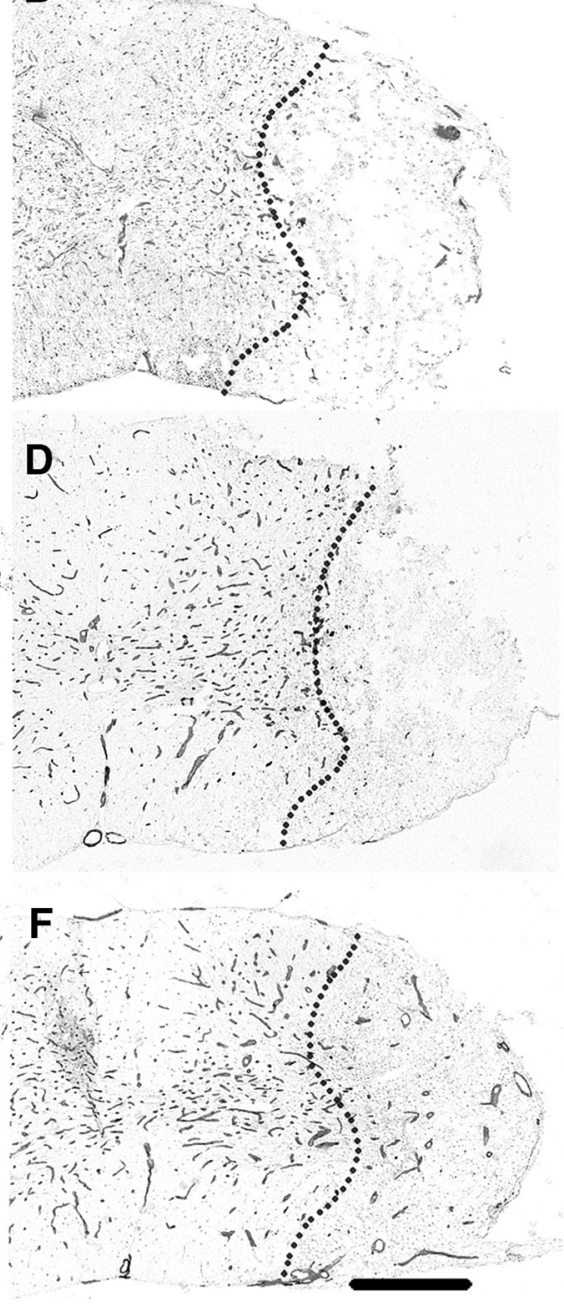

G

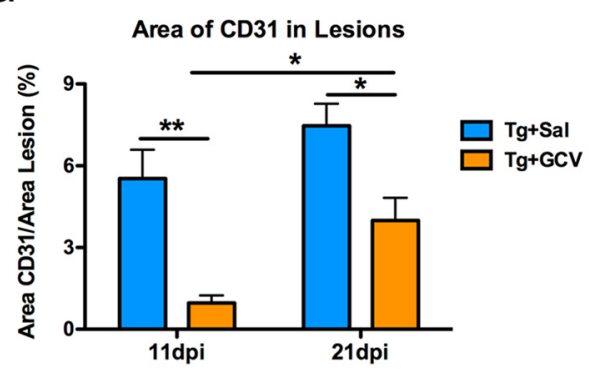

H

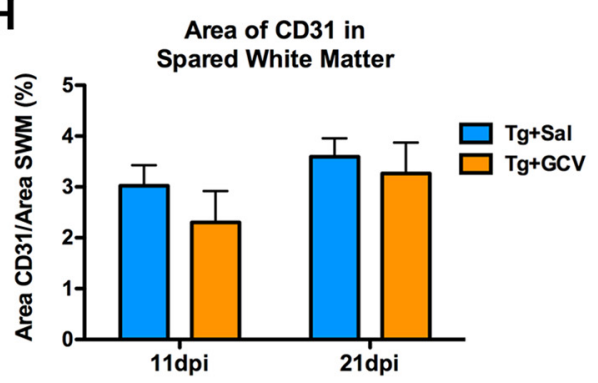

I

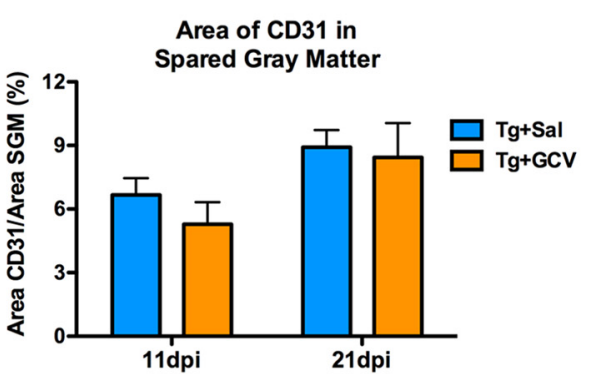

Figure 5. Loss of proliferating NG2 ${ }^{+}$cells inhibits angiogenesis in SCl lesions. $\boldsymbol{A}-\boldsymbol{F}$, Representative images of $\mathrm{CD} 31$ immunolabeling of blood vessels in $\mathrm{Tg}+\mathrm{Sal}(\boldsymbol{A}, \boldsymbol{C}, \boldsymbol{E})$ and $\mathrm{Tg}+\mathrm{GCV}(\boldsymbol{B}, \boldsymbol{D}, \boldsymbol{F})$ cross-sections at 7, 11, and 21 dpi, respectively. Lesions are to the right of the dotted lines. $G$, Quantification of the percentage area of CD31 immunolabeling inside lesions at 11 and 21 dpi. Intralesion CD31 labeling was significantly lower in $\mathrm{Tg}+\mathrm{GCV}$ tissue compared with controls at $11 \mathrm{dpi}$. CD31 did not change in controls, but increased significantly in Tg + GCV lesions by 21 dpi; however, it was still $\sim 50 \%$ lower than in control tissue. $\boldsymbol{H}, \boldsymbol{I}$, Quantification of the area of CD31 immunolabeling in spared gray matter $(\boldsymbol{H})$ and spared white matter $(\boldsymbol{I})$ at 11 and $21 \mathrm{dpi}$. There were no differences in blood vessel amount in spared tissue between groups at any time. Scale bar, $100 \mu \mathrm{m} .{ }^{*} p<0.05 ;{ }^{* *} p<0.01$.

Tg + GCV tissue, signs of edema and swelling had diminished and lesions had contracted (Fig. 4K); as a result, lesion area and total ipsilateral tissue area were now the same as controls (Fig. 4H,I). Collectively, these data show that loss of proliferating $\mathrm{NG}^{+}$cells after SCI causes excess edema, lesion swelling, and prolonged hemorrhage over the first week after injury.

\section{Loss of proliferating NG2 ${ }^{+}$pericytes prevents blood vessel growth into SCI lesions}

Angiogenesis after SCI results in new blood vessels penetrating into and throughout the fibrotic lesions. Because $\mathrm{NG}^{+}{ }^{+}$pericytes are required for peripheral angiogenesis and our time course data showed that $\mathrm{NG}_{2}{ }^{+}$pericytes (but not $\mathrm{NG}^{+}$glia) increase in lesions over 7 dpi (see Fig. $1 G$ ), the consequence of ablating proliferating NG2 ${ }^{+}$pericytes on blood vessel growth was examined by quantifying CD31 immunolabeling in lesions and spared tissue (DeLisser et al., 1997; Matsumura et al., 1997; Zhou et al., 1999). In control mice at $7 \mathrm{dpi}$, lesions already contained scattered $\mathrm{CD} 31^{+}$vessels (Fig. $5 A$ ), which increased through 11 dpi and then remained stable through $21 \mathrm{dpi}$ (Fig. 5C, E, G). Compa- rable CD31 upregulation between 7 and 11 dpi was observed in wild-type time course tissue (data not shown). In contrast, $\mathrm{CD} 31^{+}$vessels were virtually absent in lesions of $\mathrm{Tg}+\mathrm{GCV}$ mice at $7 \mathrm{~d}$ and $11 \mathrm{dpi}$ (Fig. $5 B, D$ ), revealing that the abundance of NG2 cells along lesion borders at 11 dpi had not translated into new blood vessel growth. When GCV was removed at $14 \mathrm{dpi}$ and mice survived to $21 \mathrm{dpi}, \mathrm{CD} 31^{+}$vessels increased significantly within the $\mathrm{Tg}+\mathrm{GCV}$ lesions, although there were still significantly fewer vessels than in control lesions (Fig. $5 F, G$; $\mathrm{df}=1 ; 11$ dpi $t=4.220$; 21 dpi $t=3.208$ ). CD31 labeling in spared white and gray matter was not different between groups at any time, revealing that loss of dividing $\mathrm{NG}_{2}{ }^{+}$pericytes (and glia) had no effect on blood vessels in spared tissue (Fig. $5 \mathrm{H}, \mathrm{I}$ ). These observations indicate that acute ablation of proliferating $\mathrm{NG}^{+}{ }^{+}$cells completely inhibited angiogenesis within SCI lesions and that lesion revascularization commenced after GCV removal, which allowed dividing $\mathrm{NG}_{2}{ }^{+}$cells to survive. Because $\mathrm{NG}_{2}{ }^{+}$glia do not enter lesions, it is likely that loss of dividing $\mathrm{NG} 2{ }^{+}$pericytes prevented blood vessel growth into the lesions. These data also 


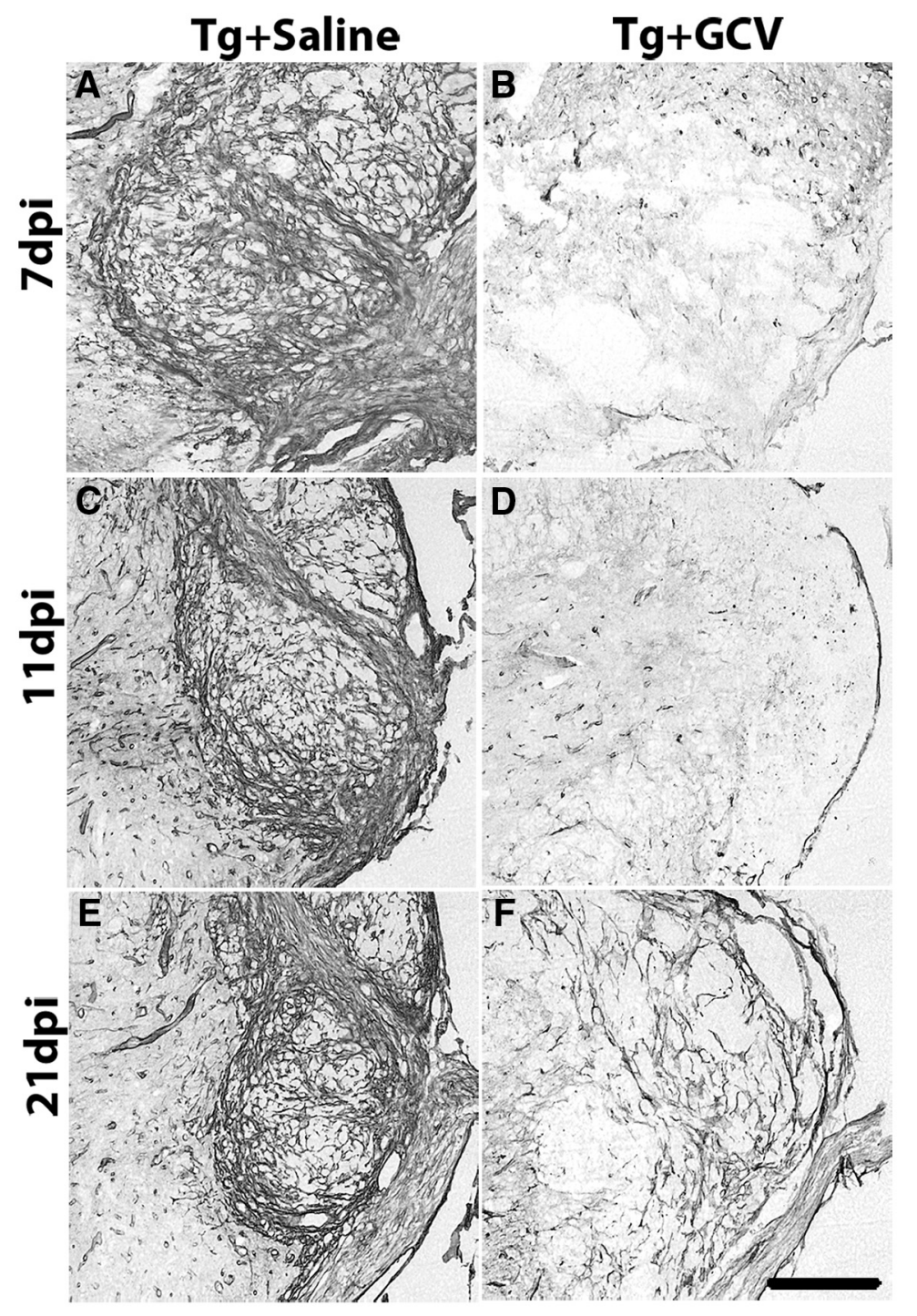

G Area of PDGFR $\beta$ in Lesions

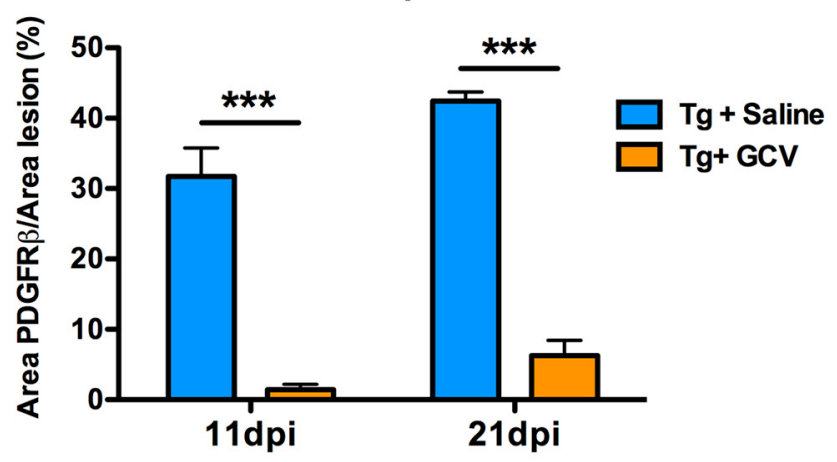

Figure 6. Proliferating NG2 ${ }^{+}$cell ablation completely prevented PDGFR $\beta$ accumulation in the lesions during GCV infusion (time of injury through $14 \mathrm{dpi}$. $\boldsymbol{A}-\boldsymbol{F}$, Representative images of lesions immunolabeled for PDGFR $\beta$ from $\mathrm{Tg}+\boldsymbol{S a l}(\boldsymbol{A}, \boldsymbol{C}, \boldsymbol{E})$ and $\mathrm{Tg}+\mathrm{GCV}(\boldsymbol{B}, \boldsymbol{D}, \boldsymbol{F})$ at 7, 11, and $21 \mathrm{dpi}$, respectively. G, Quantification of percentage area of intralesion PDGFR $\beta$ immunolabeling. The amount of PDGFR $\beta$ in Tg + GCV lesions (1-6\% of area) was significantly decreased at 11 and 21 dpi compared with control lesions (32-43\% of area). Scale bar, $50 \mu \mathrm{m}$. ${ }^{* *} p<0.001$.

suggest that, despite pericyte proliferation typically peaking at 3 dpi (Fig. 1), pericytes remained responsive to proliferative cues, at least to a limited extent, such that new vessel formation was initiated between 11 and 21 dpi.

\begin{abstract}
Ablating proliferating $\mathrm{NG}^{+}$cells causes a complete loss of PDGFR $\beta$ and laminin in the lesions
\end{abstract}

Because the fibrotic scar is thought to arise from fibrotic progenitors entering lesions along in-growing blood vessels and these vessels were absent in NG2-tk mice for at least $11 \mathrm{dpi}$, we next examined markers of tissue fibrosis within lesions. First, PDGFR $\beta$ labeling was evaluated because this is expressed by scar-forming fibroblasts after SCI (Soderblom et al., 2013). As expected, control mice demonstrated robust dense PDGFR $\beta$ labeling within the fibrotic scar by $7 \mathrm{dpi}$ that remained elevated through 21 dpi. Lesions were filled with PDGFR $\beta^{+}$ profiles, which often formed dense bands that abutted the glial scar region and traversed lesions at 7, 11, and $21 \mathrm{dpi}$ and occupied $\sim 35-40 \%$ of the lesion area (Fig. $6 A, C, E)$. In stark contrast, Tg+GCV lesions were completely devoid of PDGFR $\beta$ labeling at 7 and $11 \mathrm{dpi}$; quantification of PDGFR $\beta$ in the 11 dpi lesions showed a drastic and significant reduction in $\mathrm{Tg}+\mathrm{GCV}$ mice $(\mathrm{df}=2 ; 11 \mathrm{dpi} t=9.796$; Fig. $6 B, D, G)$. At $21 \mathrm{dpi}$ in mice that had GCV removed at $14 \mathrm{dpi}, \sim 6 \%$ of the lesion area was now occupied by sparse PDGFR $\beta^{+}$profiles in Tg+GCV lesions, but the overall amount was still $\sim 75 \%$ less than in control lesions $(\mathrm{df}=1 ; 21 \mathrm{dpi} t=$ 11.71; Fig. 6F, G).

Considering the complete loss of PDGFR $\beta$ and CD31 labeling in GCVtreated NG2-Tk mice at 7 and $11 \mathrm{dpi}$, sections were immunolabeled for laminin as a second indicator of fibrotic scar formation (and blood vessels). In control mice, laminin accumulated more slowly in lesions compared with PDGFR $\beta$. Laminin profiles were scattered throughout lesions in control mice at $7 \mathrm{dpi}$, consolidated by $11 \mathrm{dpi}$, and increased significantly at 21 dpi to occupy $\sim 45 \%$ of the lesion area (Fig. $7 A, C, E, G$ ). Similar to $\operatorname{PDGFR} \beta$, $\mathrm{Tg}+\mathrm{GCV}$ mice had sparse intralesion laminin at 7 and 11 dpi (Fig. $7 B, D$ ). By 21 $\mathrm{dpi}$, laminin had increased significantly to $33 \%$ of the lesion area in Tg+GCV lesions, but its distribution was distinct from that in controls; it was visibly less compact and did not form the dense bands that were present in control lesions (Fig. 7F, G; df $=2 ; 11$ dpi $t=4.001$ ).

\section{Ablation of proliferating NG2 ${ }^{+}$cells alters astrocytic glial scar density After SCI, proliferating NG2 ${ }^{+}$glia (and a} small number of $\mathrm{NG}_{2}{ }^{+}$pericytes) accumulate within the glial scar that surrounds the fibrotic scar. To determine whether ablating proliferating $\mathrm{NG}_{2}{ }^{+}$cells altered astrocytic glial scar formation, 11 and 21 dpi tissue was immunolabeled for GFAP (glial scar 
boundaries are still consolidating at $7 \mathrm{dpi}$, so this time point was not used for analysis). At $11 \mathrm{dpi}$, the glial border of control animals displayed a sharp continuous edge, as expected (Fig. $8 A, A^{\prime}$ ). In contrast, Tg + GCV lesions had less well defined $\mathrm{GFAP}^{+}$borders with reduced overlapping contacts between cells (Fig. $\left.8 B, B^{\prime}\right)$, similar to brain tissue surrounding the cannulation site displaying reduced GFAP in Tg-GCV mice (Fig. 2). At $21 \mathrm{dpi}$ (7 d after infusions), the sharp $\mathrm{GFAP}^{+}$border in control $\mathrm{Tg}+$ Sal mice was similar to $11 \mathrm{dpi}$ (Fig. $8 C, C^{\prime}$ ). After withdrawal of GCV in Tg+GCV mice at $14 \mathrm{dpi}$, lesion borders had begun to condense by $21 \mathrm{dpi}$, although portions of astrocytes along the edge still displayed a less-compact phenotype (Fig. $8 D, D^{\prime}$ ). This was confirmed by quantifying GFAP immunoreactivity within the glial scar, which revealed that GFAP labeling in lesion borders was significantly reduced in $\mathrm{Tg}+\mathrm{GCV}$ at $11 \mathrm{~d}$ and $21 \mathrm{dpi}$ mice compared with controls $(\mathrm{df}=2, t=3.169 ; 21$ dpi df $=1, t=3.287$; Fig. $8 E$ ).

Although the decreased astrocyte area at 11 dpi could have been due to the significantly higher NG2 cells distributed in this area at that time, this would not explain the remaining "open spaces" in the glial scar at $21 \mathrm{dpi}$ because the NG2 cell number had declined to baseline. Labeling for GFAP and CD68 revealed that the GFAP-negative spaces in $\mathrm{Tg}+\mathrm{GCV}$ were mostly filled with macrophages (Fig. $8 F, G$ ), which normally abut the astrocytic border but do not accumulate within the glial scar. Therefore, acute loss of dividing NG ${ }^{+}$cells altered the distribution of astrocytes in the lesion edge, resulting in a more discontinuous and less dense astrocyte border, which was infiltrated by macrophages.

\section{Ablating proliferating NG2 ${ }^{+}$cells acutely after SCI enhances axon growth into the lesion}

Examination of the myelin/axon-immunolabeled tissue suggested that $\mathrm{NG}^{+}{ }^{+}$cell ablation resulted in greater axon penetration into the lesions by $21 \mathrm{dpi}$ (Fig. 9A,B). To verify this, 21 dpi tissue was immunolabeled for NF and the area of axon labeling within the lesions was quantified. As expected, lesions in control tissue contained few axons at $21 \mathrm{dpi}$ (Fig. $\left.9 A^{\prime}, A^{\prime \prime}\right)$. Sections from Tg+GCV mice, however, contained numerous $\mathrm{NF}^{+}$axons throughout the lesions (Fig. $9 B^{\prime}, B^{\prime \prime}$ ). Axons were especially abundant adjacent to the lesion border/glial scar (Fig. $9 B, B^{\prime \prime}$ ), although rigorous tracing studies are needed to verify axon origin.

Quantification verified that significantly more axons were present in lesions of Tg + GCV mice compared with controls at 21 dpi $(p=0.0011$; Fig. 9C). These axons were not present in $11 \mathrm{dpi}$
Tg+Saline
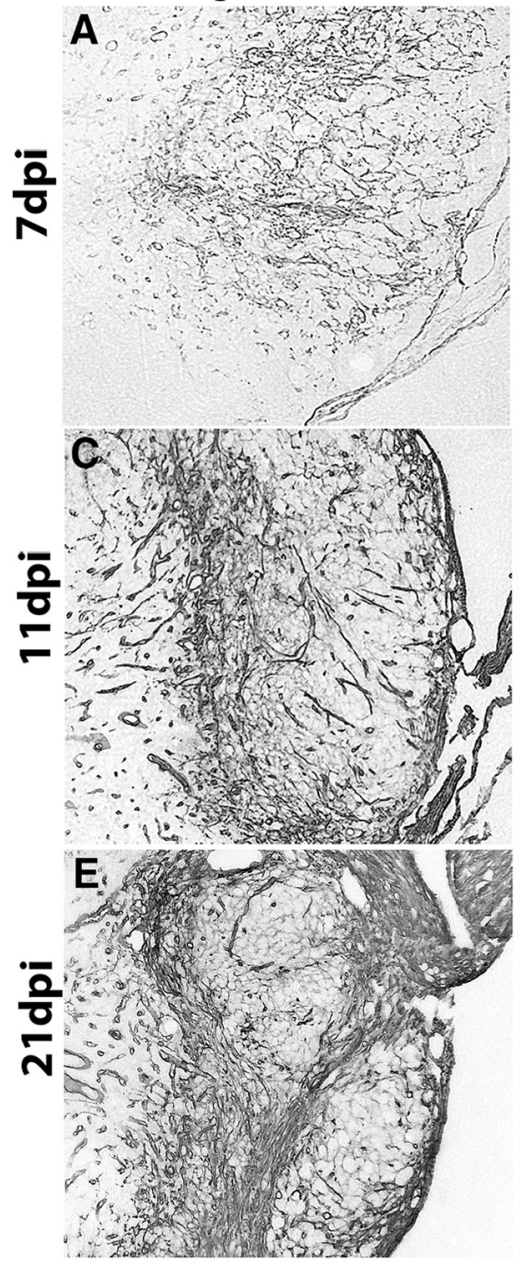

$\mathrm{Tg}+\mathrm{GCV}$

B
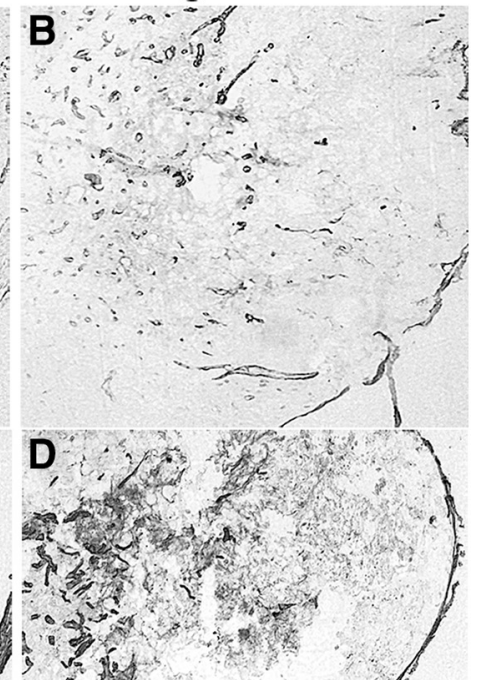
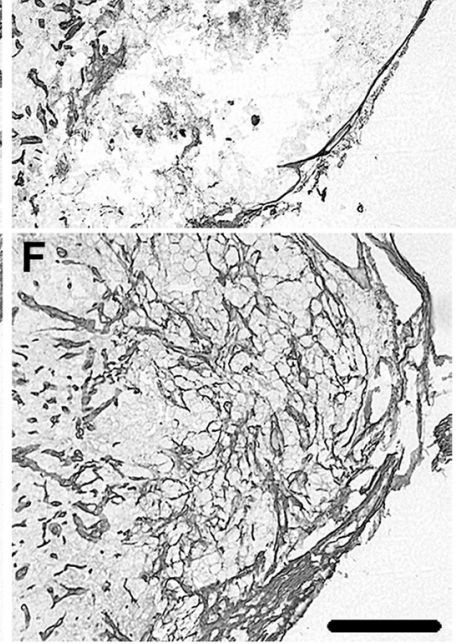

Area of Laminin in Lesions

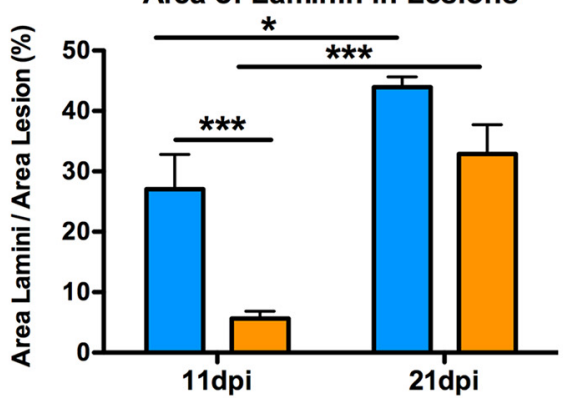

Figure 7. Proliferating $\mathrm{NG}^{+}$cell ablation caused a complete loss of intralesion laminin expression during GCV infusion (time of injury through $14 \mathrm{dpi})$. $\boldsymbol{A}-\boldsymbol{F}$, Representative images of laminin immunolabeling in $\mathrm{Tg}+\mathrm{Sal}(\boldsymbol{A}, \boldsymbol{C}, \boldsymbol{E})$ and $\mathrm{Tg}+\mathrm{GCV}(\boldsymbol{B}, \boldsymbol{D}, \boldsymbol{F})$ spinal tissue at 7, 11, and $21 \mathrm{dpi}$, respectively. $\mathbf{G}$, Quantification of the percentage area of laminin immunoreactivity within lesions. Laminin was significantly lower in $\mathrm{Tg}+\mathrm{GCV}$ lesions (6\% of lesion area) compared with controls (27\%) at $11 \mathrm{dpi}$. By $21 \mathrm{dpi}$, laminin had increased significantly in both groups and was no longer different between groups ( $\mathrm{Tg}+\mathrm{GCV}$, 33\% of lesion area; $\mathrm{Tg}+\mathrm{Sal}$, $44 \%$ of lesion area). Scale bar, $100 \mu \mathrm{m} .{ }^{*} p<0.05 ;{ }^{* * *} p<0.001$.

lesions (data not shown), indicating that axon ingrowth occurred between 11 and $21 \mathrm{dpi}$. Axons did not colocalize with GFAP or grow along astrocytic processes at $21 \mathrm{dpi}$ (data not shown).

In prior work, we noted that axons often associate with NG2 cells and processes in rat SCI lesions (McTigue et al., 2006). Therefore, $21 \mathrm{dpi}$ sections here were colabeled for NF and NG2. In lesion borders of both $\mathrm{Tg}+\mathrm{Sal}$ and $\mathrm{Tg}+\mathrm{GCV}$ mice, axons were commonly in contact with $\mathrm{NG}^{+}$processes (Fig. 9D,E). In addition, axons penetrating the lesions of Tg + GCV mice commonly associated with $\mathrm{NG} 2{ }^{+}$cells and some completely surrounded NG2 ${ }^{+}$cell bodies and 

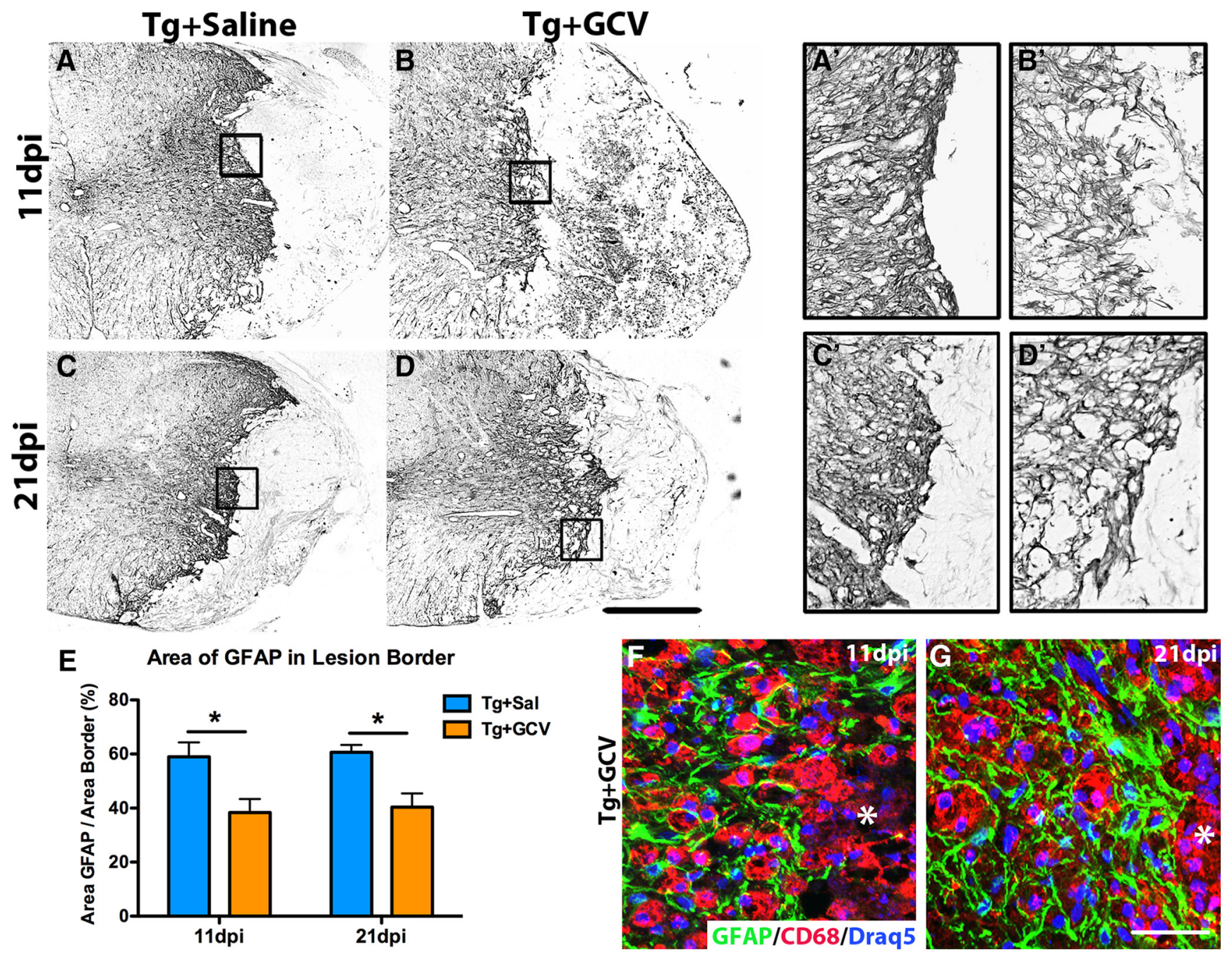

Figure 8. Acute ablation of proliferating NG2 ${ }^{+}$cells changes the subsequent astrocytic glial scar. $\boldsymbol{A}-\boldsymbol{D}$, Representative images of GFAP labeling in $\mathrm{Tg}+\mathrm{Sal}(\boldsymbol{A}, \boldsymbol{C})$ and $\mathrm{Tg}+\mathrm{GCV}(\boldsymbol{B}, \boldsymbol{D})$ ipsilateral sections at 11 and $21 \mathrm{dpi}$, respectively, with higher power views of boxes shown in $\boldsymbol{A}^{\prime}-\boldsymbol{D}^{\prime}$. Note the decreased GFAP and lack of a sharp edge in $\mathrm{Tg}+\mathrm{GCV}$ tissue at $11 \mathrm{dpi}\left(\boldsymbol{B}^{\prime}\right)$ compared with the stereotypical tightly compacted border in control tissue $\left(\boldsymbol{A}^{\prime}\right)$. $\boldsymbol{E}$, Percentage area of GFAP immunolabeling in lesion borders was significantly reduced in $\mathrm{Tg}+\mathrm{GCV}$ ( $\sim 40 \%$ of scar area) compared with controls at 11 or $21 \mathrm{dpi}$ ( $\sim 60 \%$ of scar area). $\boldsymbol{F}, \mathbf{G}$, Confocal images of glial scar from 11 and $21 \mathrm{dpi} \mathrm{Tg}+\mathrm{GCV}$ cords labeled for GFAP (green), CD68 (red), and Draq5 (blue counterstain). Spaces lacking GFAP in glial scars of $\mathrm{Tg}+\mathrm{GCV}$ mice were mostly filled with $\mathrm{CD} 8^{+}$macrophages at 11 and 21 dpi. Scale bar, $50 \mu \mathrm{m} .{ }^{*} p<0.05$.

appeared to travel along NG2 ${ }^{+}$processes (Fig. $9 E, F$ ). These results show that enhanced axon growth into lesions occurred between 11 and 21 dpi after removal of GCV at 14 dpi, suggesting that glial and fibrotic scars were more growth permissive during this time compared with controls. This is potentially due to the increased NG2 cells and processes along lesions borders at $11 \mathrm{dpi}$ and/or the less dense glial and fibrotic scars in Tg + GCV mice. Indeed, as shown in Figures 6 and 7, in control sections, PDGFR $\beta$ and laminin both form dense bands adjacent and perpendicular to the glial scar, which may present a less growth-permissive terrain.

Summary: low-magnification comparison demonstrates profound multicellular disruption by loss of proliferating $\mathrm{NG} 2{ }^{+}$cells after SCI

For a holistic overview of how the noted cellular changes relate to one another, low-magnification images of serial sections at the epicenter are presented in Figure 10, which shows adjacent sections from one representative mouse in each group (WT $+\mathrm{GCV}$, $\mathrm{Tg}+\mathrm{Sal}$, and $\mathrm{Tg}+\mathrm{GCV}$ ) at 11 and $21 \mathrm{dpi}$. From this view, it is clear that the acute loss of proliferating $\mathrm{NG}^{+}$cells caused a profound disruption of major cell populations by $11 \mathrm{dpi}$ (com- parable changes occurred at $7 \mathrm{dpi}$, data not shown). The lesion border as demarcated by EC/NF, GFAP, and NG2 was altered and there was a near complete loss of intralesion angiogenesis and fibrotic scar as shown by lack of CD31, PDGFR $\beta$, and laminin labeling at $11 \mathrm{dpi}$. At $21 \mathrm{dpi}$ ( 1 week after GCV removal) in GCV-treated tissue, the lesion border and glial scar were more distinct and a significant amount of laminin had been deposited in the lesions, although blood vessels and PDGFR $\beta$ labeling were still reduced compared with controls. The partial recovery of cell and tissue dynamics by $21 \mathrm{dpi}$ in $\mathrm{Tg}+\mathrm{GCV}$ mice demonstrate that the acute presence of proliferating NG2 ${ }^{+}$cells affects directly or indirectly the response of astrocytes, new blood vessels, axons, and fibrotic cells after SCI.

The numbers of macrophages in the lesions were not different. Although the low-power image of $\mathrm{Cd} 11 \mathrm{~b}$ at $11 \mathrm{dpi}$ appears to show reduced macrophages, the lesions are larger at this time and quantification revealed that the overall level of CD68 in the lesions at this time and at 21 dpi was comparable between groups. We did note, however, that microglial reactivity was significantly greater in spared gray matter adjacent to the lesion in Tg-GCV tissue (data not shown). 

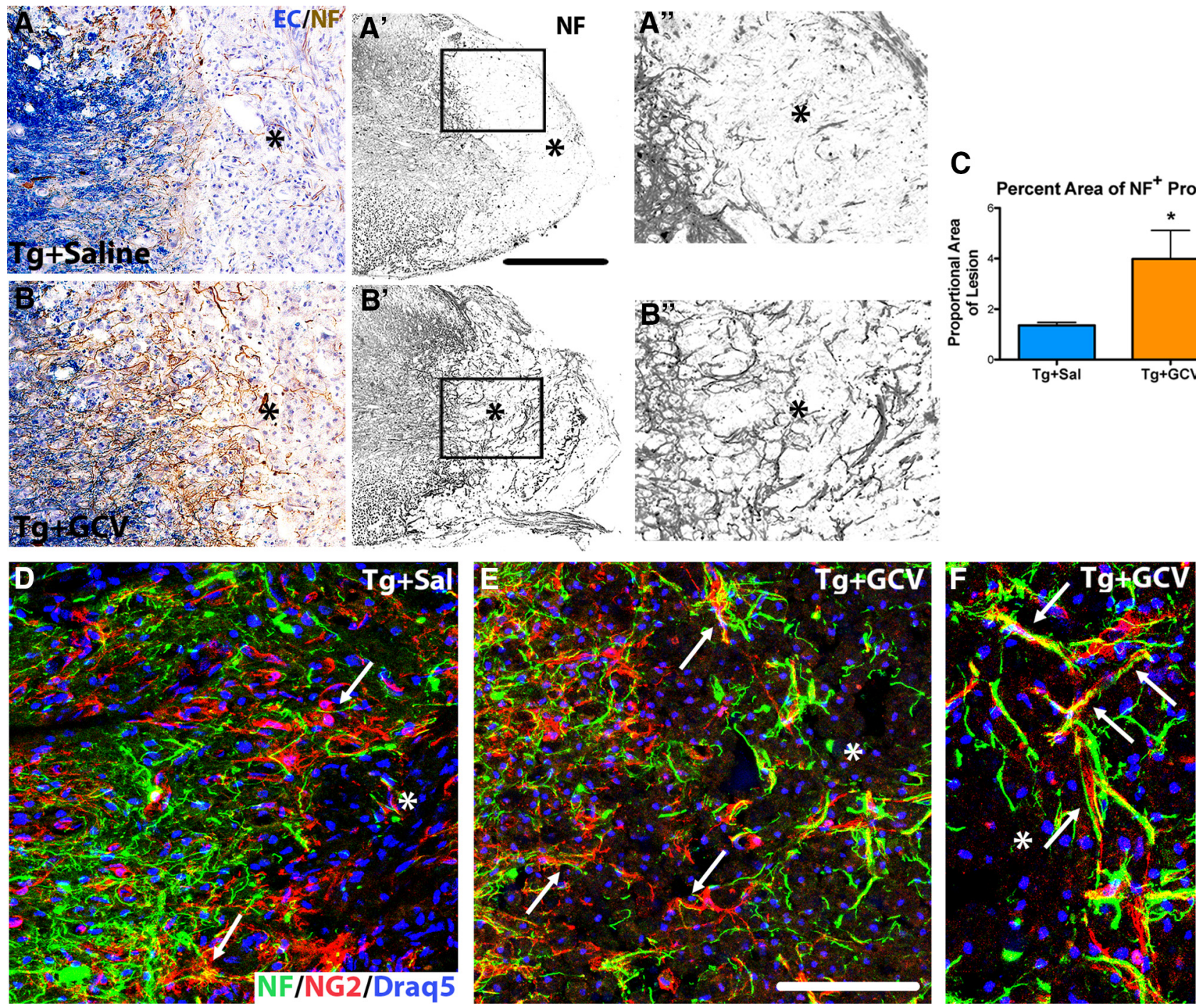

Figure 9. Ablating proliferating NG2 ${ }^{+}$cells after $S C l$ enhances subsequent axon growth into the lesions between 11 and $21 \mathrm{dpi}$. $\boldsymbol{A}, \boldsymbol{B}$, Representative images of axon immunolabeling in $\mathrm{Tg}+\mathrm{Sal}$ $\left(\boldsymbol{A}, \boldsymbol{A}^{\prime}, \boldsymbol{A}^{\prime \prime}\right)$ and $\mathrm{Tg}+\mathrm{GCV}\left(\boldsymbol{B}, \boldsymbol{B}^{\prime}, \boldsymbol{B}^{\prime \prime}\right)$ in ipsilateral spinal tissue at $21 \mathrm{dpi}$., $\mathrm{Tg}+\mathrm{GCV}$ mice had a significantly increased area of NF labeling in lesions by $21 \mathrm{dpi}$ ( $\sim 4 \%$ of lesion area) compared with controls ( $\sim 1.5 \%$ lesion area). $\boldsymbol{D}-\boldsymbol{F}$, Confocal images of $\mathrm{Tg}+\mathrm{Sal}$ and $\mathrm{Tg}+\mathrm{GCV}$ sections labeled for NF (green), NG2 (red), and nuclei (Draq5, blue) at $21 \mathrm{dpi}$. In both groups, axons in the lesion border closely associate with $\mathrm{NG2}^{+}$cells. $\boldsymbol{E}$, $\boldsymbol{F}$, Within lesions of $\mathrm{Tg}+\mathrm{GCV}$ mice, some axons completely surround $\mathrm{NG2}{ }^{+}$cell bodies and appear to travel along NG2 ${ }^{+}$processes. $\boldsymbol{D}$ and $\boldsymbol{E}$ show comparable regions of the lesion border from a control and GCV-treated mouse. $F$ shows a representative image from the center of the lesion core of a $\mathrm{Tg}+\mathrm{GCV}$ cord. Asterisks in images denote lesions. Scale bars: $A, B, 100 \mu \mathrm{m} ; \boldsymbol{D}, \boldsymbol{E}, 20 \mu \mathrm{m} .{ }^{*} p<0.05$.

A few additional trends can be noted from the low-power serial sections: (1) labeling for GFAP and NG2 share similar domains along the lesion border, although the pattern for intralesion NG2 labeling is more similar to PDGFR $\beta$ and laminin, particularly along the fibrous bands that traverse the lesion in control animals; (2) the glial scar is distinctively different from and abuts the fibrotic scar (as noted before); (3) intralesion labeling for PDGFR $\beta$ and laminin demonstrate a near complete overlap at 11 and $21 \mathrm{dpi}$, except at $21 \mathrm{dpi}$ in $\mathrm{Tg}+\mathrm{GCV}$ tissue, when laminin labeling far exceeds that of PDGFR $\beta$. This is notable because laminin accumulation was delayed compared with PDGFR $\beta$ deposition in control mice, yet it accumulated more rapidly in lesions of $\mathrm{Tg}+\mathrm{GCV}$ mice. Therefore, the origin of each molecule and signals driving their deposition must be different based on time after injury and presence or absence of acute $\mathrm{NG} 2{ }^{+}$cells.
Acute ablation of proliferating NG2 ${ }^{+}$cells impairs forelimb step length recovery after cervical SCI

To assess changes in forelimb locomotor recovery after cervical unilateral contusion, right and left forelimb step length was measured in uninjured wild-type mice, $\mathrm{WT}+\mathrm{GCV}, \mathrm{Tg}+\mathrm{Sal}$, and $\mathrm{Tg}+\mathrm{GCV}$ mice. At $7 \mathrm{dpi}$, all injured mice displayed a significant decrease in forelimb step length bilaterally compared with naive, revealing that the deficits were injury induced and not due to GCV (right: $\mathrm{df}=4$; WT $+\mathrm{GCV} t=3.987 ; \mathrm{Tg}+\mathrm{Sal} t=4.163$; $\mathrm{Tg}+\mathrm{GCV} t=4.374$; left: $\mathrm{df}=4$; WT+GCV $t=4.002$; Tg+Sal $t=4.104$; $\mathrm{Tg}+\mathrm{GCV} t=4.117$; Fig. $11 \mathrm{~A}, B)$. In Tg+Sal control mice, step length in both forelimbs recovered over time and was not significantly different from uninjured mice at 11 or $21 \mathrm{dpi}$. In contrast, forelimb step length in Tg + GCV remained significantly decreased at $11 \mathrm{dpi}$ and shortened further by $21 \mathrm{dpi}$, when it became significantly different from $\mathrm{Tg}+\mathrm{Sal}$ and naive (right: $\mathrm{df}=4 ; 11 \mathrm{dpi} t=5.135 ; 21 \mathrm{dpi} \mathrm{Tg}+\mathrm{Sal} t=4.193 ; 21 \mathrm{dpi}$ naive 


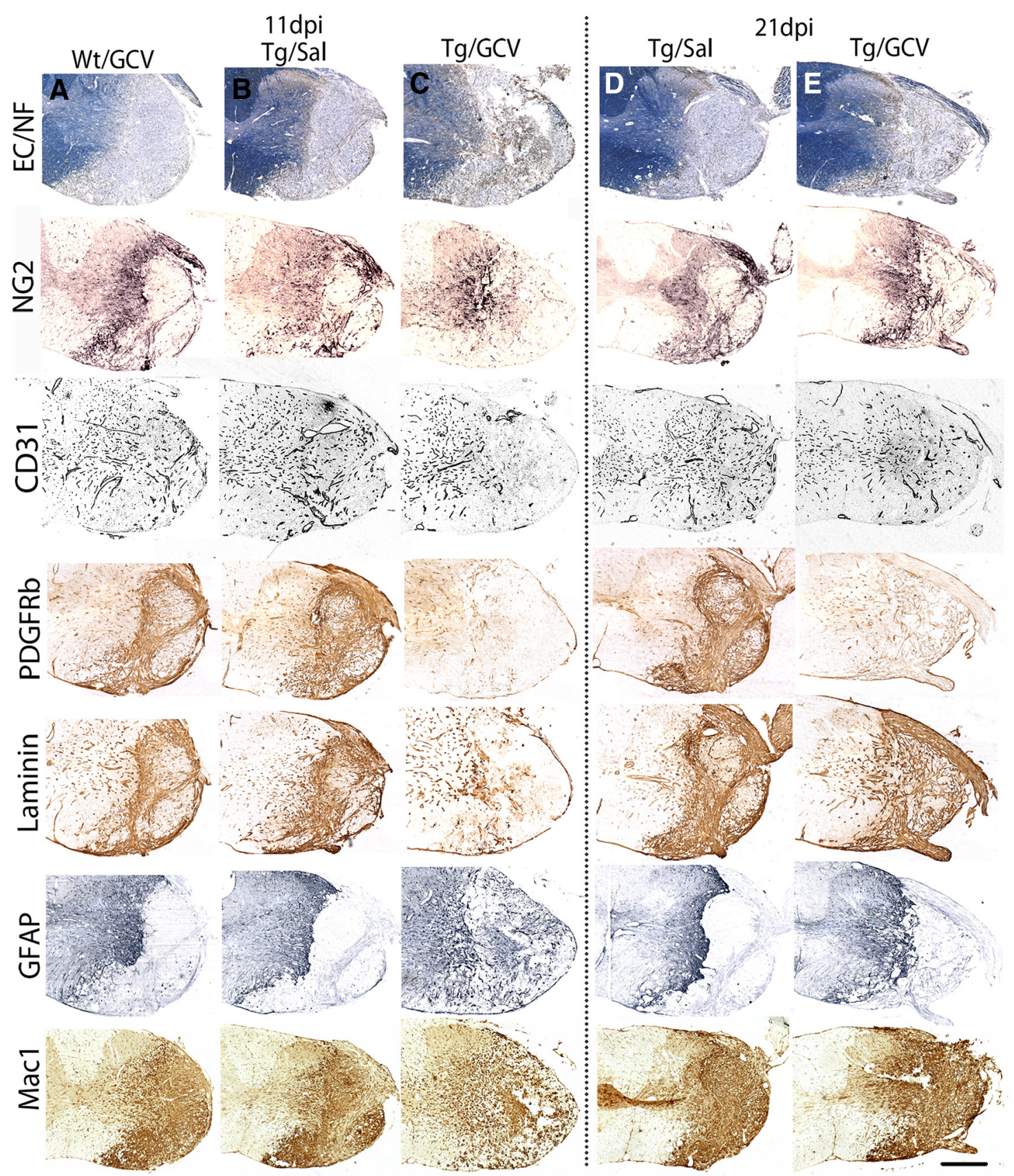

Figure 10. Low-magnification image comparison after SCI demonstrates the multicellular changes caused by loss of acutely proliferating NG2 ${ }^{+}$cells. Images are from adjacent sections immunolabeled for myelin (blue; EC) and axons (brown; NF), NG2, CD31, PDGFR $\beta$, laminin GFAP, and Mac1 (Cd11b) from WT + GCV (A), Tg + Sal (B), and Tg + GCV (C) tissue at 11 dpi and for Tg + Sal (D) and $\mathrm{Tg}+\mathrm{GCV}(\boldsymbol{E})$ tissue at 21 dpi. Scale bar, $200 \mu \mathrm{m}$.

$t=6.373 ;$ left: $\mathrm{df}=4 ; 11 \mathrm{dpi} t=4.895 ; 21 \mathrm{dpi} \mathrm{Tg}+\mathrm{Sal} t=$ 4.894; 21 dpi naive $t=6.626$; Fig. $11 A, B)$. This significant reduction in step length at $21 \mathrm{dpi}$ was observed in two replicate studies. Therefore, reducing proliferating $\mathrm{NG}^{+}$cells after cervical unilateral contusion persistently impaired recovery of forelimb step length.

\section{Discussion}

The role of astrocytes and fibroblasts in post-SCI scar formation has received much attention. Here, we predicted that $\mathrm{NG}^{+}{ }^{+}$glia and pericytes also influence scar formation. $\mathrm{NG}^{+}$glia accumulate along the lesion border but do not enter lesions in mice, so their direct influence is likely restricted to glial scars. $\mathrm{NG}^{+}{ }^{+}$peri- cytes are $\sim 10$-fold less abundant, but also proliferate after SCI and do enter lesions, where they increase $>20$-fold between 1 and 7 dpi. Given the disparate number and distribution of $\mathrm{NG}^{+}$glia and pericytes, we used NG2-Tk mice to examine both scars after ablating dividing $\mathrm{NG}^{+}$cells.

Our model reduced $\mathrm{NG} 2{ }^{+}$cells $\sim 40 \%$ by $7 \mathrm{dpi}$, which, interestingly, corresponds with the $41 \%$ recombination rate in cervical spinal cord. NG2 ${ }^{+}$cell loss exacerbated edema and prolonged hemorrhage, revealing that $\mathrm{NG}^{+}$cells (likely pericytes) are important for acute hemostasis. Over the next $4 \mathrm{~d}, \mathrm{NG}^{+}$cell numbers rebounded along lesion borders to greater than control levels despite ongoing GCV treatment, suggesting that nonrecombined 
NG2 cells underwent rapid replacement between 7 and $11 \mathrm{dpi}$. This is consistent with work showing the rapidity with which $\mathrm{NG}^{+}$glial cells replace lost neighbors (Hughes et al., 2013). Increased lesion border $\mathrm{NG}_{2}{ }^{+}$cells at 11 dpi correlated with 30\% more oligodendrocytes compared with controls, likely a "side effect" of robust $\mathrm{NG} 2^{+}$glia accumulation (Rosenberg et al., 2008). Despite excess NG2 ${ }^{+}$cells at $11 \mathrm{dpi}$, lesions were still larger due to edema and contained no blood vessels or fibrotic scar elements. Mice that had GCV discontinued at $14 \mathrm{dpi}$ and survived until $21 \mathrm{dpi}$ to determine the tissue responses revealed that the NG2 cell number in the glial scar had normalized and lesions had contracted to control levels. However, several striking differences in the tissue remained, revealing that early loss of dividing NG2 ${ }^{+}$ cells set a different course for cellular reactions that was not reversed by NG2 cell replacement, at least not through $21 \mathrm{dpi}$. Specific details are described next.

\section{Postinjury angiogenesis depends on} proliferating $\mathrm{NG}^{+}{ }^{+}$pericytes

Pericytes are mural cells embedded within the vascular basement membrane. They migrate ahead of endothelial cells and guide sprouting vessels by secreting VEGF (Bergers and Song, 2005). Here, pericyte proliferation peaked at $3 \mathrm{dpi}$, of which $30 \%$ expressed NG2 and would be vulnerable to GCV. Because pericytes are critical for BBB integrity, their loss likely mediated the sustained intraspinal bleeding and edema (Ozerdem et al., 2001; Armulik et al., 2010; Bell et al., 2010).

$\mathrm{NG}_{2}{ }^{+}$pericytes are required for neovascularization in development and tumors (Ozerdem and Stallcup, 2003; Huang et al., 2010). Our data extend these findings, showing that post-SCI lesion revascularization also requires proliferating $\mathrm{NG}^{+}$cells. Because $\mathrm{NG}_{2}{ }^{+}$glia did not enter lesions, $\mathrm{NG}^{+}$pericytes must mediate this angiogenesis. Although $\mathrm{NG}^{+}$glia regulate developmental angiogenesis through Wnt signaling (Yuen et al., 2014), blood vessel number in spared tissue was unaffected by $\mathrm{NG}^{+}$ cell loss or replacement. This suggests that altered $\mathrm{NG}^{+}$glial numbers did not affect spared (or new) vessels within the lesion border. Although pericytes may influence $\mathrm{NG}^{+}$glia formation after demyelination (De La Fuente et al., 2017), the similar loss of $\mathrm{NG} 2{ }^{+}$glia and pericytes at $7 \mathrm{dpi}$ and large rebound by $11 \mathrm{dpi}$ makes it impossible to discern the relationship between these cell populations in the current model.

\section{$\mathrm{NG}^{+}$cell-dependent angiogenesis regulates fibrotic} scar formation

It was demonstrated previously that Glast ${ }^{+}$"Type A" pericytes produce scar fibroblasts (Göritz et al., 2011). Using a spinal transection model, those investigators reported pericytes increase by 5 dpi and inhibiting Glast ${ }^{+}$pericyte proliferation abolished the fibrotic scar. They postulated that pericytes enter lesions upon growing blood vessels and then detach and differentiate into fibrotic PDGFR $\beta^{+}$cells.

Another study characterized fibrotic scar progenitors as $\operatorname{PDGFR} \beta^{+}$coll $\alpha 1$-expressing NG2-negative perivascular fibroblasts, and the investigators hypothesized that these were the Glast ${ }^{+}$pericytes in the above study (Soderblom et al., 2013). In combination with our results, this suggests that two populations of pericytes are needed for scar formation: the $\mathrm{NG}^{+}$pericytes required for angiogenesis and the NG2-negative PDGFR $\beta^{+}$pericytes that become scar-forming fibroblasts. This is consistent with the greater PDGFR $\beta$ in lesions compared with NG2 noted here (see summary Fig. 10) and is also consistent with the peak in $\mathrm{NG} 2{ }^{+}$-vessel-wrapping pericytes in lesions and robust PDGFR $\beta$ profiles by 7 dpi noted here. We posit that ablating dividing $\mathrm{NG} 2{ }^{+}$pericytes prevented vessel growth into lesions, thereby abolishing the physical structure on which the scar-forming cells enter lesions. Accordingly, it was only after blood vessels formed in GCV-treated lesions that fibrotic components were deposited, showing a strong correlation between post-SCI angiogenesis and fibrosis.

Recent work suggests fibrotic scar formation depends on hematogenous macrophages rather than angiogenesis (Zhu et al., 2015). Here, lesions of GCV - and saline-treated mice had similar macrophage density at $11 \mathrm{dpi}$. Despite this, fibrotic scar and blood vessels had not formed in GCV-treated mice, revealing that macrophages alone were insufficient to trigger these processes. 
Other work suggests that fibrosis requires macrophages and angiogenesis (Wynn and Vannella, 2016). Therefore, angiogenesis appears to be a prerequisite for post-SCI fibrosis and perhaps a minimum number of macrophages is needed before fibrotic scar formation commences.

\section{Proliferating NG2 ${ }^{+}$cell loss alters glial scar density}

Proliferating $\mathrm{NG}_{2}{ }^{+}$cell loss rendered glial scars less dense with less distinct borders at 11-21 dpi, which could be due to reduced fibrosis and/or fewer NG2 ${ }^{+}$glia at $7 \mathrm{dpi}$. Glial and fibrotic scars segregate via bidirectional signaling between astrocytes and fibroblasts, producing a sharp boundary between them (Bundesen et al., 2003). Here, loss of the fibrotic scar would eliminate this signaling and could impair strict glial scar boundaries. However, compact glial scars can form without fibrotic scars, suggesting that additional mechanisms are involved (Göritz et al., 2011). For instance, $\mathrm{NG} 2^{+}$glia release $\beta$-catenin, which promotes post-SCI astrocyte hypertrophy (Rodriguez et al., 2014). Significantly reduced NG2 ${ }^{+}$glia at 7 dpi may have lowered acute $\beta$-catenin sufficiently to affect subsequent astrocyte responses. Because $\mathrm{NG2}^{+}$glia can release other mediators such as cytokines (Moyon et al., 2015), they may influence stereotypical glial scar formation through multiple mechanisms.

Reactive astrocytes "corral" fibroblasts and macrophages and loss of post-SCI astrocytes allows macrophages to penetrate spared tissue (Faulkner et al., 2004; Wanner et al., 2013). Our results show that $\mathrm{NG}_{2}{ }^{+}$cell ablation produced astrocytic scars in which GFAP-negative areas were largely filled with macrophages. This did not reduce spared tissue area, however, in contrast to proliferating astrocyte ablation (Faulkner et al., 2004), revealing a subtler effect of $\mathrm{NG} 2^{+}$cell loss.

\section{$\mathrm{NG}^{+}$cell ablation increased axon growth into lesions}

Unexpectedly, ablating proliferating $\mathrm{NG}^{+}$cells acutely promoted subsequent axon growth into lesions. This is likely an indirect effect because $\mathrm{NG}^{+}$cells were greater than in controls by $11 \mathrm{dpi}$, but axons did not enter lesions until after that time. Many axons appeared to sprout in/around the glial scar and entered lesions closely associated with $\mathrm{NG}_{2}{ }^{+}$profiles that increased in lesions along the same time, reminiscent of work using rat SCI models (McTigue et al., 2006, Busch et al., 2010). Some studies suggest that NG2 inhibits neurite growth and that $\mathrm{NG}^{+}$cells form synaptic contacts with axons that prevent further growth (Ughrin et al., 2003; Tan et al., 2006; Petrosyan et al., 2013; Filous et al., 2014), whereas others suggest that $\mathrm{NG}^{+}$cells stabilize dystrophic axons and promote axon growth in vivo (de Castro et al., 2005; Yang et al., 2006; Busch et al., 2010). Here, dense NG2 in lesion borders at 11 dpi clearly did not prevent axons from entering the lesions.

Increased neurite growth in Tg+GCV mice may result from the disrupted glial scar over the first $11 \mathrm{~d}$, allowing axons to initially penetrate lesions (Menet et al., 2003), followed by formation of a less fibrous laminin-rich lesion core. Reducing (but not eliminating) post-SCI fibrosis promotes axon growth (Klapka and Müller, 2006; Zhu et al., 2015), suggesting that a similar situation may have arisen in our model. Future work is needed to verify axon source and specific mechanisms inducing their growth.

\section{Proliferating NG2 ${ }^{+}$cells are necessary for functional recovery}

A compelling observation was persistent deficits in forelimb function. Forelimb step length decreased in control mice at $7 \mathrm{dpi}$ but recovered to baseline by $11 \mathrm{dpi}$, whereas it continued to worsen in Tg+GCV mice even after GCV removal. This is surprising because tissue sparing and neuron number were comparable to controls. Persistent locomotor deficits may reflect neuronal dysfunction, possibly due to altered microglial reactivity as we noted significantly enhanced microglial reactivity in Tg-GCV spared tissue (data not shown). Because microglia can induce neurotoxicity through factors such as TNF $\alpha$ (Furling et al., 2000; Olmos and Llado, 2014; Li et al., 2017), the local environment may have had aberrant neurochemistry that impaired neuron function. Whatever the mechanism, it is clear that losing proliferating NG2 ${ }^{+}$ cells acutely after SCI induced sufficient cellular dysfunction to cause persistent motor deficits.

\section{Summary}

These data emphasize that $\mathrm{NG}^{+}$cells directly or indirectly influence multiple aspects of the post-SCI milieu, including hemorrhage, angiogenesis, fibrotic scar formation, laminin deposition, astrocyte responses, and axon growth. The different distribution and number of proliferating $\mathrm{NG}_{2}{ }^{+}$glia and pericytes provides some indications about their functions, but future studies manipulating each population independently are needed to further clarify specific roles. Clearly, intercellular interactions in the damaged CNS among glia, fibroblasts, and blood vessels are complex and will require further study to unravel completely.

\section{References}

Armulik A, Genové G, Mäe M, Nisancioglu MH, Wallgard E, Niaudet C, He L, Norlin J, Lindblom P, Strittmatter K, Johansson BR, Betsholtz C (2010) Pericytes regulate the blood-brain barrier. Nature 468:557-561. CrossRef Medline

Bell RD, Winkler EA, Sagare AP, Singh I, LaRue B, Deane R, Zlokovic BV (2010) Pericytes control key neurovascular functions and neuronal phenotype in the adult brain and during brain aging. Neuron 68:409-427. CrossRef Medline

Bergers G, Song S (2005) The role of pericytes in blood-vessel formation and maintenance. Neuro Oncol 7:452-464. CrossRef Medline

Bundesen LQ, Scheel TA, Bregman BS, Kromer LF (2003) Ephrin-B2 and EphB2 regulation of astrocyte-meningeal fibroblast interactions in response to spinal cord lesions in adult rats. J Neurosci 23:7789-7800. Medline

Busch SA, Horn KP, Cuascut FX, Hawthorne AL, Bai L, Miller RH, Silver J (2010) Adult NG2 ${ }^{+}$cells are permissive to neurite outgrowth and stabilize sensory axons during macrophage-induced axonal dieback after spinal cord injury. J Neurosci 30:255-265. CrossRef Medline

Bush TG, Savidge TC, Freeman TC, Cox HJ, Campbell EA, Mucke L, Johnson MH, Sofroniew MV (1998) Fulminant jejuno-ileitis following ablation of enteric glia in adult transgenic mice. Cell 93:189-201. CrossRef Medline

Buss A, Pech K, Kakulas BA, Martin D, Schoenen J, Noth J, Brook GA (2009) NG2 and phosphacan are present in the astroglial scar after human traumatic spinal cord injury. BMC Neurol 9:32. CrossRef Medline

Church JS, Kigerl KA, Lerch JK, Popovich PG, McTigue DM (2016) TLR4 deficiency impairs oligodendrocyte formation in the injured spinal cord. J Neurosci 36:6352-6364. CrossRef Medline

Darby IA, Hewitson TD (2007) Fibroblast differentiation in wound healing and fibrosis. Int Rev Cytol 257:143-179. CrossRef Medline

de Castro R Jr, Tajrishi R, Claros J, Stallcup WB (2005) Differential responses of spinal axons to transection: influence of the NG2 proteoglycan. Exp Neurol 192:299-309. CrossRef Medline

De La Fuente AG, Lange S, Silva ME, Gonzalez GA, Tempfer H, van Wijngaarden P, Zhao C, Di Canio L, Trost A, Bieler L, Zaunmair P, Rotheneichner P, O’Sullivan A, Couillard-Despres S, Errea O, Mäe MA, Andrae J, He L, Keller A, Bátiz LF, Betsholtz C, Aigner L, Franklin RJM, Rivera FJ (2017) Pericytes stimulate oligodendrocyte progenitor cell differentiation during CNS remyelination. Cell Rep 20:1755-1764. CrossRef Medline

DeLisser HM, Christofidou-Solomidou M, Strieter RM, Burdick MD, Robinson CS, Wexler RS, Kerr JS, Garlanda C, Merwin JR, Madri JA, Albelda SM (1997) Involvement of endothelial PECAM-1/CD31 in angiogenesis. Am J Pathol 151:671-677. Medline

Faulkner JR, Herrmann JE, Woo MJ, Tansey KE, Doan NB, Sofroniew MV 
(2004) Reactive astrocytes protect tissue and preserve function after spinal cord injury. J Neurosci 24:2143-2155. CrossRef Medline

Filous AR, Tran A, Howell CJ, Busch SA, Evans TA, Stallcup WB, Kang SH, Bergles DE, Lee SI, Levine JM, Silver J (2014) Entrapment via synapticlike connections between NG2 proteoglycan + cells and dystrophic axons in the lesion plays a role in regeneration failure after spinal cord injury. J Neurosci 34:16369-16384. CrossRef Medline

Furling D, Ghribi O, Lahsaini A, Mirault ME, Massicotte G (2000) Impairement of synaptic transmission by transient hypoxia in hippocampal slices: Improved recovery in glutathione peroxidase transgenic mice. Proc Natl Acad Sci U S A 97:4351-4356. CrossRef Medline

Göritz C, Dias DO, Tomilin N, Barbacid M, Shupliakov O, Frisén J (2011) A pericyte origin of spinal cord scar tissue. Science 333:238-242. CrossRef Medline

Gowing G, Vallières L, Julien JP (2006) Mouse model for ablation of proliferating microglia in acute CNS injuries. Glia 53:331-337. CrossRef Medline

Hackett AR, Lee JK (2016) Understanding the NG2 glial scar after spinal cord injury. Front Neurol 7:199. Medline

Hesp ZC, Goldstein EA, Miranda CJ, Kaspar BK, McTigue DM (2015) Chronic oligodendrogenesis and remyelination after spinal cord injury in mice and rats. J Neurosci 35:1274-1290. CrossRef Medline

Huang FJ, You WK, Bonaldo P, Seyfried TN, Pasquale EB, Stallcup WB (2010) Pericyte deficiencies lead to aberrant tumor vascularizaton in the brain of the NG2 null mouse. Dev Biol 344;1035-1046. CrossRef Medline

Hughes EG, Kang SH, Fukaya M, Bergles DE (2013) Oligodendrocyte progenitors balance growth with self-repulsion to achieve homeostasis in the adult brain. Nat Neurosci 16:668-676. CrossRef Medline

Jakeman LB, Guan Z, Wei P, Ponnappan R, Dzwonczyk R, Popovich PG, Stokes BT (2000) Traumatic spinal cord injury produced by controlled contusion in mouse. J Neurotrauma 17:299-319. CrossRef Medline

Jakeman LB, Williams KE, Brautigam B (2014) In the presence of danger: the extracellular matrix defensive response to central nervous system injury. Neural Regen Res 9:377-384. CrossRef Medline

Kang SH, Li Y, Fukaya M, Lorenzini I, Cleveland DW, Ostrow LW, Rothstein JD, Bergles DE (2013) Degeneration and impaired regeneration of gray matter oligodendrocytes in amyotrophic lateral sclerosis. Nat Neurosci 16:571-579. CrossRef Medline

Klapka N, Müller HW (2006) Collagen matrix in spinal cord injury. J Neurotrauma 23:422-435. CrossRef Medline

Klapka N, Hermanns S, Straten G, Masanneck C, Duis S, Hamers FP, Müller D, Zuschratter W, Müller HW (2005) Suppression of fibrous scarring in spinal cord injury of rat promotes long-distance regeneration of corticospinal tract axons, rescue of primary motoneurons in somatosensory cortex and significant functional recovery. Eur J Neurosci 22:3047-3058. CrossRef Medline

Li Y, Lucas-Osma AM, Black S, Bandet MV, Stephens MJ, Vavrek R, Sanelli L, Fenrich KK, Di Narzo AF, Dracheva S, Winship IR, Fouad K, Bennett DJ (2017) Pericytes impair capillary blood flow and motor function after chronic spinal cord injury. Nat Med 23:733-741. CrossRef Medline

Loy DN, Crawford CH, Darnall JB, Burke DA, Onifer SM, Whittemore SR (2002) Temporal progression of angiogenesis and basal lamina deposition after contusive spinal cord injury in the adult rat. J Comp Neurol 445:308-324. CrossRef Medline

Matsumura T, Wolff K, Petzelbauer P (1997) Endothelial cell tube formation depends on cadherin 5 and CD31 interactions with filamentous actin. J Immunol 158:3408-3416. Medline

Mautes AE, Weinzierl MR, Donovan F, Noble LJ (2000) Vascular events after spinal cord injury: contribution to secondary pathogenesis. Phys Ther 80:673-687. Medline

McTigue DM, Tripathi R, Wei P (2006) NG2 co-localizes with axons and is expressed by a mixed cell population in spinal cord lesions. J Neuropathol Exp Neurol 65:406-420. CrossRef Medline

Menet V, Prieto M, Privat A, Giménez y Ribotta M (2003) Axonal plasticity and functional recovery after spinal cord injury in mice deficient in both glial fibrillary acidic protein and vimentin genes. Proc Natl Acad Sci U S A 100:8999-9004. CrossRef Medline

Moyon S, Dubessy AL, Aigrot MS, Trotter M, Huang JK, Dauphinot L, Potier MC, Kerninon C, Melik Parsadaniantz S, Franklin RJ, Lubetzki C (2015) Demyelination causes adult CNS progenitors to revert to an immature state and express immune cues that support their migration. J Neurosci 35:4-20. CrossRef Medline
Olmos G, Llado J (2014) Tumor necrosis factor alpha: a link between neuroinflammation and excitotoxicity. Mediators Inflamm 2014:861231. CrossRef

Ozerdem U, Stallcup WB (2003) Early contribution of pericytes to angiogenic sprouting and tube formation. Angiogenesis 6:241-249. CrossRef Medline

Ozerdem U, Grako KA, Dahlin-Huppe K, Monosov E, Stallcup WB (2001) NG2 proteoglycan is expressed exclusively by mural cells during vascular morphogenesis. Dev Dyn 222:218-227. CrossRef Medline

Petrosyan HA, Hunanyan AS, Alessi V, Schnell L, Levine J, Arvanian VL (2013) Neutralization of inhibitory molecule NG2 improves synaptic transmission, retrograde transport, and locomotor function after spinal cord injury in adult rats. J Neurosci 33:4032-4043. CrossRef Medline

Rodriguez JP, Coulter M, Miotke J, Meyer RL, Takemaru K, Levine JM (2014) Abrogation of $\beta$-catenin signaling in oligodendrocyte precursor cells reduces glial scarring and promotes axon regeneration after CNS injury. J Neurosci 34:10285-10297. CrossRef Medline

Rosenberg SS, Kelland EE, Tokar E, De la Torre AR, Chan JR (2008) The geometric and spatial constraints of the microenvironment induce oligodendrocyte differentiation. Proc Natl Acad Sci U S A 105:14662-14667. CrossRef Medline

Schonberg DL, Popovich PG, McTigue DM (2007) Oligodendrocyte generation is differentially influenced by toll-like receptor (TLR) 2 and TLR4mediated intraspinal macrophage activation. J Neuropathol Exp Neurol 66:1124-1135. CrossRef Medline

Serwanski DR, Jukkola P, Nishiyama A (2017) Heterogeneity of astrocyte and NG2 cell insertion at the node of Ranvier. J Comp Neurol 525:535552. CrossRef Medline

Soderblom C, Luo X, Blumenthal E, Bray E, Lyapichev K, Ramos J, Krishnan V, Lai-Hsu C, Park KK, Tsoulfas P, Lee JK (2013) Perivascular fibroblasts form the fibrotic scar after contusive spinal cord injury. J Neurosci 33:13882-13887. CrossRef Medline

Tan AM, Zhang W, Levine JM (2005) NG2: a component of the glial scar that inhibits axon growth. J Anat 207:717-725. CrossRef Medline

Tan AM, Colletti M, Rorai AT, Skene JH, Levine JM (2006) Antibodies against the NG2 proteoglycan promote the regeneration of sensory axons within the dorsal columns of the spinal cord. J Neurosci 26:4729-4739. CrossRef Medline

Tomicic MT, Thust R, Kaina B (2002) Ganciclovir-induced apoptosis in HSV-1 thymidine kinase expressing cells: critical role of DNA breaks, Bcl-2 decline and caspase-9 activation. Oncogene 21:2141-2153. CrossRef Medline

Tripathi R, McTigue DM (2007) Prominent oligodendrocyte genesis along the border of spinal contusion lesions. Glia 55:698-711. CrossRef Medline

Ughrin YM, Chen ZJ, Levine JM (2003) Multiple regions of the NG2 proteoglycan inhibit neurite growth and induce growth cone collapse. J Neurosci 23:175-186. Medline

Wanner IB, Anderson MA, Song B, Levine J, Fernandez A, Gray-Thompson Z, Ao Y, Sofroniew MV (2013) Glial scar borders are formed by newly proliferated, elongated astrocytes that interact to corral inflammatory and fibrotic cells via STAT3-dependent mechanisms after spinal cord injury. J Neurosci 33:12870-12886. CrossRef Medline

Wynn TA, Vannella KM (2016) Macrophages in tissue repair, regeneration, and fibrosis. Immunity 44:450-462. CrossRef Medline

Yang Z, Suzuki R, Daniels SB, Brunquell CB, Sala CJ, Nishiyama A (2006) NG2 glial cells provide a favorable substrate for growing axons. J Neurosci 26:3829-3839. CrossRef Medline

Yuen TJ, Silbereis JC, Griveau A, Chang SM, Daneman R, Fancy SPJ, Zahed H, Maltepe E, Rowitch DH (2014) Oligodendrocyte-encoded HIF function couples postnatal myelination and white matter angiogenesis. Cell 158:383-396. CrossRef Medline

Zhou Z, Christofidou-Solomidou M, Garlanda C, DeLisser HM (1999) Antibody against murine PECAM-1 inhibits tumor angiogenesis in mice. Angiogenesis 3:181-188. CrossRef Medline

Zhu X, Bergles DE, Nishiyama A (2008) NG2 cells generate both oligodendrocytes and gray matter astrocytes. Development 135:145-157. Medline

Zhu Y, Soderblom C, Krishnan V, Ashbaugh J, Bethea JR, Lee JK (2015) Hematogenous macrophage depletion reduces the fibrotic scar and increases axonal growth after spinal cord injury. Neurobiol Dis 74:114-125. CrossRef Medline 